\title{
Nanotheranosties
}

2018; 2(1): 42-58. doi: 10.7150/ntno.19974

Review

\section{Upregulation of osteogenesis of mesenchymal stem cells with virus-based thin films}

\author{
Huong Giang Nguyen, ${ }^{1,2}$ Kamolrat Metavarayuth, ${ }^{1}$ Qian Wang ${ }^{\bowtie}$ \\ 1. Department of Chemistry and Biochemistry, University of South Carolina, 631 Sumter Street, Columbia, SC 29208, USA \\ 2. National Institute of Standards and Technology, 100 Bureau Drive, Gaithersburg, MD 20899, USA \\ $\triangle$ Corresponding authors: Email: wang263@mailbox.sc.edu \\ (c) Ivyspring International Publisher. This is an open access article distributed under the terms of the Creative Commons Attribution (CC BY-NC) license \\ (https://creativecommons.org/licenses/by-nc/4.0/). See http://ivyspring.com/terms for full terms and conditions.
}

Received: 2017.03.07; Accepted: 2017.10.15; Published: 2018.01.01

\begin{abstract}
A major aim of tissue engineering is to develop biomimetic scaffolding materials that can guide the proliferation, self-renewal and differentiation of multipotent stem cells into specific lineages. Cellular functions can be controlled by the interactions between cells and biomaterials. Therefore, the surface chemistry and topography of support materials play a pivotal role in modulating cell behaviors at many stages of cell growth and development. Due to their highly ordered structure and programmable surface chemistries, which provide unique topography as biomaterials, viral nanoparticles have been utilized as building blocks for targeted cell growth and differentiation. This review article discusses the fabrication of two-dimensional virus-based thin film on substrates and highlights the study of the effect of chemical and physical cues introduced by plant virus nanoparticle thin films on the promotion of osteogenic differentiation of BMSCs.
\end{abstract}

Key words: Plant virus, viral nanoparticles, thin-film, osteogenic differentiation, mesenchymal stem cells

\section{Introduction}

A major aim in tissue engineering is the development of biomimetic scaffolding materials that can guide the proliferation, self-renewal and differentiation of multipotent stem cells into specific lineages. Stem cells can be collected from adipose tissue, bone marrow, placenta, and skeletal muscles.[1] Bone marrow derived mesenchymal stem cells (BMSCs) are a sub-population of non-hematopoietic bone marrow stroma,[2-4] which have the capability to self-renew and differentiate to various lineages, such as adipocytes, osteocytes, chondrocytes, hepatocytes, neurons, muscle cells, and epithelial cells.[4-9] Due to their pluripotent potential, less controversial use than embryonic stem cells, ease of isolation, and rapid expansion,[10] BMSCs are an ideal source of adult stem cells to study material-mediated differentiation.

Many cellular functions are dictated by the interactions between cells and biomaterials.[11-13] Cell-material interactions can direct cell shape and cytoskeletal organization, which in turn control biological processes, such as cell adhesion, growth, differentiation, and apoptosis.[14-17] Mammalian cells can sense and interact with the extracellular microenvironment at the nanometer scale despite their micrometer dimensions.[18, 19] Consequently, the surface chemistry and topography of support materials play a pivotal role in modulating cell behaviors at many stages of cell growth and development.[13, 20-28] The interactions of cells with nanometric surfaces often lead to a series of gene and protein regulation events that start as early as the cells begin to sense their surrounding environment.[28] Therefore, understanding the various topographical cues that are responsible for cellular behaviors is key to applications, such as regenerative medicine and tissue engineering. These applications require the engineering of a programmable two- or three-dimensional biomaterial with micro and/or nanometer features that could mimic certain aspects of the extracellular environment such as the spatial arrangement and density of ligands. [16, 20, 29] One 
class of such biomaterials is virus, protein assemblies that offer nanoscale surface morphology and polyvalent ligand display.[30] Hence, virus nanoparticles have emerged as attractive building blocks for targeted cell growth and differentiation.[31-35]

Virus nanoparticles are typically comprised of self-assembled coat protein subunits, which form the virus capsid that encapsulates the genomic RNA. Figure 1 shows the structural features of some representative viruses. Viral nanoparticles can be categorized into three groups based on their particle shapes: (1) rod shape virus, (2) filamentous virus, and (3) spherical virus. In comparison to other substrates such as synthetic polymer, polysaccharides, and peptide assemblies, virus nanoparticles offer several advantages. First, they possess uniform size, highly ordered and well-resolved 3D structure, and high harvesting yield and purity.[36, 37] The symmetrical arrangement of the viral coat proteins makes virus particles an ideal scaffold for displaying identical copies of functional groups for multivalent ligand display. Furthermore, the chemical and genetic modifications of virus surfaces to incorporate new functional groups have been extensively studied, which provides a library of viruses with different surface properties.[31-33, 38]

The surface nanotopography and polyvalent nature of viruses can be exploited to tune cellular response. A great number of studies have demonstrated the promotion of osteogenic differentiation of BMSCs by two dimensional (2D) virus thin film coated substrates. Based on the extensive amount of work reported, this review highlights the effect of chemical and physical cues introduced by virus nanoparticles on the osteogenesis of mesenchymal stem cells. The fabrications of virus thin films by the drop-coating and the layer-by-layer methods are compared. The influences of viral particle shapes, nanoscale features, and surface chemistry on the osteogenesis of BMSCs by utilizing substrates fabricated from several different wild-type, modified, and mutant viruses will be discussed in details, with the goal of delineating, where possible, the effect of each factor. With this review, we would like to highlight the special nanotopographical features offered by the virus substrate and how such kind of materials can be employed to direct cell differentiations for research and tissue engineering applications.
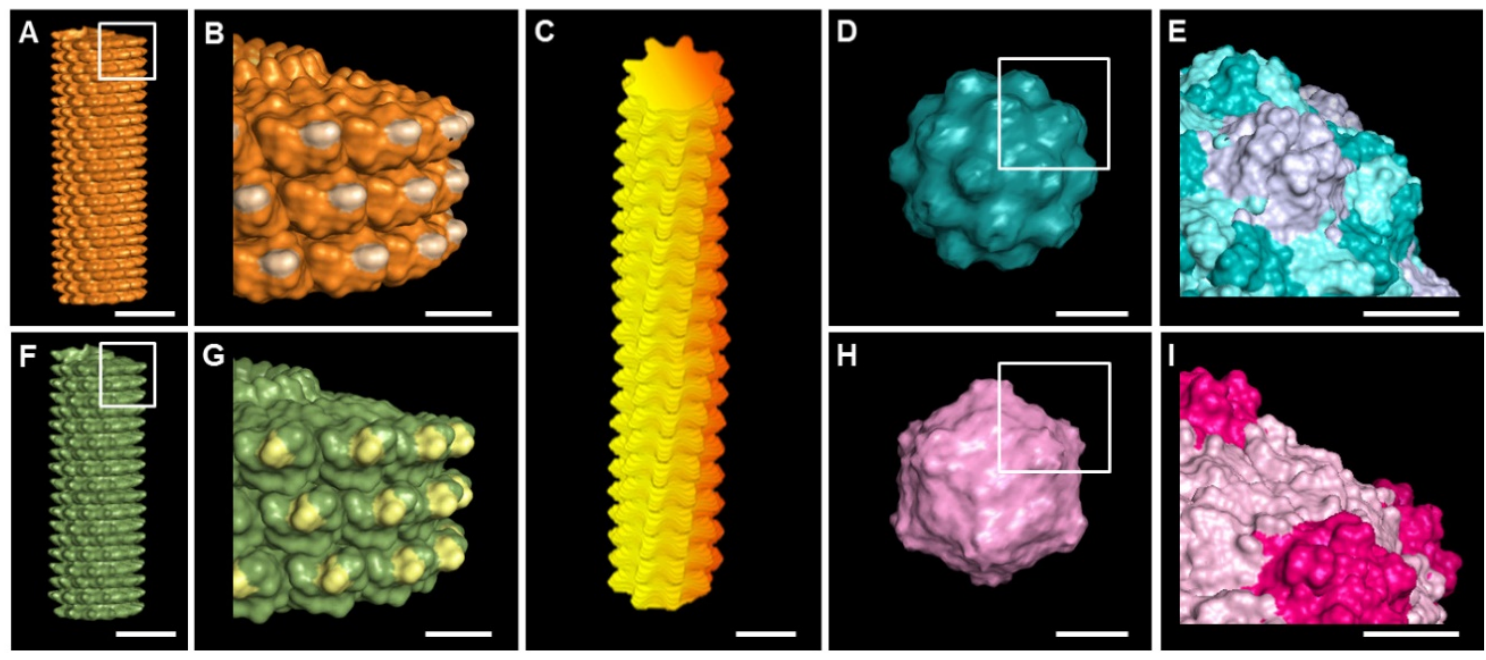

\begin{tabular}{|c|c|c|c|c|c|c|c|}
\hline Virus & Symmetry & Dimensions & pI & $\begin{array}{l}\text { Number of } \\
\text { subunits }\end{array}$ & $\begin{array}{l}\text { MW of } \\
\text { subunit (Da) }\end{array}$ & Size of genome (Da) & $\begin{array}{l}\text { Viral classification } \\
\text { (genus) }\end{array}$ \\
\hline $\begin{array}{l}\text { Tobacco mosaic } \\
\text { virus (TMV) }\end{array}$ & Helical & $300 \times 18 \mathrm{~nm}$ & 3.5 & 2130 & $17 \mathrm{kDa}$ & ssRNA $6.3 \mathrm{~kb}$ & Tobamovirus \\
\hline $\begin{array}{l}\text { Turnip yellow } \\
\text { mosaic virus } \\
\text { (TYMV) }\end{array}$ & Icosahedral & $\sim 28 \mathrm{~nm}$ & $3.77-3.95$ & 180 & $20 \mathrm{kDa}$ & $1.9 \times 10^{6} \mathrm{Da}$ & Tymovirus group \\
\hline $\begin{array}{l}\text { Cowpea mosaic } \\
\text { virus (CPMV) }\end{array}$ & Icosahedral & $\sim 28 \mathrm{~nm}$ & 5.5 & $\begin{array}{l}60 \mathrm{~L} \text { and } 60 \mathrm{~S} \\
\text { subunits }\end{array}$ & $\begin{array}{l}40-45 \mathrm{kDa} \text { and } \\
21-27 \mathrm{kDa}\end{array}$ & $\begin{array}{l}2 \operatorname{ssRN} \wedge \mathrm{s} \\
\left(3.94 \times 10^{\circ} \mathrm{Da}\right) \\
\left.5.16 \times 10^{6} \text { and } 5.98 \times 10^{6} \mathrm{Da}\right)\end{array}$ & Comovirus \\
\hline $\begin{array}{l}\text { Turnip vein } \\
\text { clcaning virus } \\
\text { (TVCV) }\end{array}$ & Rod & $300 \times 18 \mathrm{~nm}$ & 3.55 & $\sim 2000$ & $17 \mathrm{kDa}$ & Positive sense RNA, $6.3 \mathrm{~kb}$ & Tobamovirus \\
\hline $\begin{array}{l}\text { Potato virus } X \\
(\text { PVX) }\end{array}$ & Filamentous & $470-580 \times 5 \mathrm{~nm}$ & 4.4 & 1300 & $18 \mathrm{kDa}$ & Single ssRNA $(5.9-7.0 \mathrm{~kb})$ & Potexvirus \\
\hline
\end{tabular}

Figure 1. (A-I) Molecular models showing surface topography of typical plant viruses discussed in this review. (A-B) Tobacco mosaic virus (TMV); (C) Potato virus X (PVX); (D-E) Turnip yellow mosaic virus (TYMV); (F-G) Turnip vein clearing virus (TVCV); (H-I) Cowpea mosaic virus (CPMV). Scale bar indicates 10 nm in (A, C, D, F and $\mathbf{H}$ ) and $5 \mathrm{~nm}$ in (B, E, G and I). The models were generated using Pymol (www.pymol.org) with co-ordinates obtained from RCSB protein data bank. Reproduced with permission from ref 36. Copyright 2015 Wiley Online Library. 


\section{Biomaterials Surface Modification by Virus Thin Films}

Typically, for cell studies, two-dimensional virus thin-films can be fabricated using one of two methods: 1) drop-coating (or dip-coating) and 2) layer-by-layer (LbL) assembly. Both methods rely on the charged surface of the virus nanoparticles to electrostatically coat the virus on the surface. At neutral $\mathrm{pH}$, the virus nanoparticles have surface charges due to the net excess of either negatively or positively charged amino acids, such as the negatively-charged aspartic acid and glutamic acid or the positively-charged lysine, arginine, and histidine.

A

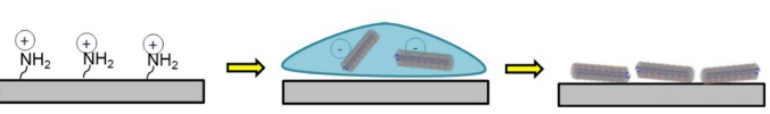

B

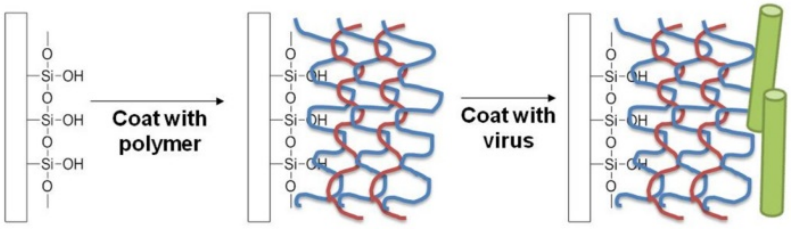

Figure 2. Schematic illustration of the two typical methods to fabricate virus thin films. (A) Drop coating or dip-coating of viral thin films via electrostatic attractions. (B) Layer-by-layer approach with polyelectrolytes.

\section{Direct deposition via electrostatic interactions}

Given that most viral particles have a surface charge at neutral $\mathrm{pH}$ (see the $\mathrm{pI}$ values of selected viral particles in Figure 1), they can be directly deposited via electrostatic interactions onto surfaces containing oppositely charged functional groups. For example, tobacco mosaic virus (TMV), turnip vein clearing virus (TVCV), potato virus $\mathrm{X}$ (PVX), turnip yellow mosaic virus (TYMV), and cowpea mosaic virus (CPMV) all have isoelectric points (pI) below 5.5 , leading to an overall negative particle surface charge at neutral $\mathrm{pH}$ condition. Thus, surfaces containing positively charged functional groups could provide the interactions strong enough to adsorb the negatively charged viral particles.

Kaur et al. developed a drop-coating protocol, in which glass slide modified with aminopropyltriethoxysilane (APTES) was utilized to construct virus-coated substrates.[1] The primary amine functional group of APTES presents a positive charge upon protonation under neutral condition. This coating method involves dropping a small amount of aqueous virus solution on the silanized glass, which is then left to dry under a sterile tissue culture hood. TYMV, TMV, TMV-Phosphate, and TMV-RGD were all successfully coated on silanized glass using this method. However, while this method results in high coverage of virus nanoparticles on the substrate surface, the coating protocol is very tedious due to many careful cycles of washing and drying, requires skillful personnel to prepare the substrates, and suffers from the bad reproducibility. Furthermore, coffee ring effect, whereby a circular pattern is left after a puddle of particle-laden liquid evaporates, was also commonly detected on the substrates prepared by this method if the virus solution did not fully cover the substrate.[39] A thicker virus layer could be detected around the edge and only non-uniform coatings were obtained, which led to un-predictable roughness of the substrates.

To avoid the coffee ring effect, Matavarayuth et al. tested 12-well plates with amine-conjugated surface (poly-d-lysine (PDL)), an alternative positively charged surface, for virus coating.[40] With this material, the procedure for coating is easier than silanized glass but a consistent and uniform coating could not be achieved either. In particular, during the drying process, more virus particles were drawn to the wall of the well, leaving the center of each well with much less virus particle. Nevertheless, atomic force microscopy (AFM) micrographs confirmed the presence of viral particles on the PDL-coated surface and revealed a nearly complete coverage of substrates by intact viral particles. The virus particles were mostly randomly adsorbed on the PDL-coated 12-well plates with some area of the virus-coated substrates exhibiting directional virus coating, which could be attributed to the natural irregularity of the cell culture surface of 12-well plate. With this method, five different types of viruses were successfully coated onto the surface of the well plate. Root mean square roughness analysis of virus-coated substrates from data collected from AFM micrographs $(\mathrm{n}=4)$ indicated that there is no significant difference of microscale roughness among the different virus-coated substrates.

\section{Fabrication of virus thin films by layer-by-layer deposition method}

In contrast to the non-uniform coating that may result from the drop-coating method, electrostatically driven layer-by-layer (LbL) deposition has been reported to generate a virus nanoparticle coating in a controllable and reproducible manner while maintaining the integrity of the virus nanoparticle.[41-45] The LbL method involves coating alternating layers of positively charged and negatively charged polymers, called polyelectrolytes, before the final coating with the building block of interest. Since polyelectrolytes are polymers with electrolyte-bearing repeating units (i.e. polycations or 
polyanions), they have properties of both polymers and electrolytes. Given that polycations and polyanions can interact and form polyelectrolyte complexes,[46, 47] Drecher et al. demonstrated in the 1990s that by simply depositing alternating layers of polycations and polyanions, he could use the LbL technique to form polyelectrolyte multilayer films (PEMs) with the ability to change the surface charge of the resulting film to the same charge as that of the final polyelectrolyte layer.[48] For the purpose of fabricating $2 \mathrm{D}$ virus thin film, the last polyelectrolyte coating typically has a charge in contrast to that of the virus nanoparticle surface charge in order to attract the virus nanoparticles. In a way, the virus nanoparticle can be considered a weak polyelectrolyte due to its surface charge.

The thickness of each deposited layer using the LbL assembly technique is influenced by several factors, which include solvent quality,[49] temperature,[50, 51] salt concentration,[52] $\mathrm{pH}$,[53] and polyelectrolyte charge density.[54] PEM thickness and mass increase linearity with the number of deposited layers $N$ under salt-free conditions, whereas they exponentially rise with $N$ at high salt conditions.[55] Since the LbL deposition process is a surface charge dominated adsorption process, altering the polymer solution $\mathrm{pH}$, which adjusts the degree ionization of the polymer functional group in a pKa-dependent manner, can also change the thickness of the PEM.[53] Therefore, salt addition and the $\mathrm{pH}$ adjustment to near the isoelectric point ( $\mathrm{pI}$ ) of the polymer solution should increase the amount of viral particles adsorbed.

Despite the benefit of a stable, uniform layer of virus coating, few studies have successfully grown stem cells on virus-coated substrates using the LbL technique potentially due to the poor biocompatibility of certain polyelectrolytes with stem cells in vitro. Indeed, the choice of the polyelectrolytes appears to be crucial for cell studies. For example, poor biocompatibility was observed on TMV-coated substrate when poly(diallyl dimethyl ammonium chloride) (PDDA) and poly(styrene sulfonate) (PSS) were used as polyelectrolytes.[56] In one successful study, Zan et al. coated TYMV-RGD44, a genetic mutant of TYMV, on substrate using the LbL technique for BSMCs studies.[57] The PEM consisted of alternating layers of poly(allyamine) hydrochloride (PAH) and poly(acrylic acid) (PAA), chosen for their good biocompatibility. The greatest coverage of TYMV-RGD44 (pI 3.7) on the PEM terminating in $\mathrm{PAH}$ was achieved when the virus solution $\mathrm{pH}$ was 4 , close to the isoelectric point of the virus. In another study, Lee et al. successfully assembled TMV- and TMV-RGD1-coated substrates by depositing a virus layer on a 7-layer PEM film of alternating PAH and PSS and used those virus-coated thin films for stem cell studies.[58] In an unpublished study, the PSS-PAH and PAA-PAH pairs of polyelectrolytes were tested for fabrication of the five virus particles coated substrates. Interestingly, while both of the polyelectrolytes pairs gave uniform coating with high coverage of virus particles, cells could not survive on the LbL substrates after a few days of culturing.[59] These results suggest the development of biocompatible polyelectrolytes is necessary for the LbL method to be fully applicable for long-term stem cell studies.

\section{Viral Particle Coated Substrates Promote Osteogenesis of MSCs}

Naturally available in different sizes, shapes, and a wide array of coat protein surface chemistries, virus nanoparticles are ideal building blocks to study the effect of nanoscale topographies on the differentiation of BMSCs. Unsurprisingly, many of the early studies looked at naturally occurring, or wild-type virus nanoparticles.

\section{Virus thin film can promote osteogenesis of BMSCs}

The promotion of osteogenesis of BMSCs was first reported for silanized tissue culture plastic drop-coated with turnip yellow mosaic virus (TYMV), an icosahedral virus around $28 \mathrm{~nm}$ in diameter.[1] The TYMV coated substrate was not only able to support the osteogenic differentiation of BMSCs, but it also induced cell maturation and an increase in mineralization 7 days earlier compared to control substrate with no virus coating. BMSCs cultured on the TYMV-coated substrate formed nodular structures starting at day 7. Since alkaline phosphatase (ALP) is a marker enzyme for cells undergoing differentiation from pre-osteoblast to osteoblast, the nodular structures were tested for ALP activity.[1] The cells around the nodules showed strong staining for ALP activity, while the nodule exhibited weak ALP activity. This was attributed to the fact that while ALP level increases during proliferation and maximizes during mineralization, it declines in heavily mineralized cell cultures, suggesting that the cells have already begun mineralization.[1] The mineralization was confirmed by Alizarin Red staining, which detected calcium deposition from mineralization. In addition, real-time quantitative PCR (RT-qPCR) showed that the expression of the non-collagen gene, osteocalcin, an osteoblast differentiation and mineralization specific marker, was upregulated 690 folds for cells grown on the TYMV-coated substrate at day 14, while that for 
cells grown on control substrate took 21 days before reaching only 400 folds expression level. Expressed only during the post-proliferative period, osteocalcin reaches its maximum expression during mineralization and accumulates in the mineralized bone.[60-62]

To determine if virus nanoparticles resembling fibrillar proteins in the extracelluar matrix (EMC) could also temporally improve the osteogenic differentiation of BMSCs, a later study showed that substrate covered by rod shape tobacco mosaic virus (TMV) upregulated osteo-specific genes, such osteocalcin, and osteopontin, in addition to bone morphogenetic protein-2 (BMP2), an early osteogenic marker.[63, 64] Osteopontin, another early marker of osteoblastic differentiation, is a bone protein that serves as a bridge between the cells and the hydroxyapatite through the RGD and polyaspartate sequences in its structure.[65] Maximum osteo-specific gene expression was achieve day 14, which was 7 days earlier than BMSCs cultured on tissue culture plastic (TCP). The importance of the surface provided by the virus particle was supported by a follow-up study, which confirmed that cell culture media supplemented with TMV solution failed to mediate osteogenesis, suggesting that the virus did not act as soluble inducer.[63]

\section{Effect of virus particle shape and virus surface nanoscale topography on stem cells differentiation}

Given that the initial studies indicated that two different virus particles could promote osteogenic differentiation, it was ambiguous whether the shape of the virus nanoparticle, the nanoscale topography provided by the surface chemistries of the virus particle, or the combination of the two is responsible for providing the cues crucial for the enhanced osteogenesis. In an attempt to delineate this, a study was conducted in which five viral nanoparticles with distinct morphology and nanotopography were used to generate a series of plant virus nanoparticle coated substrates to investigate cellular responses to the different types of topographical cues. Of the five viruses employed, two were rod-shaped (TMV and TCVV), one was filamentous (PVX), and two were spherical (CPMV and TYMV) (Figure 1). The two combinations of same-shape (and dimensions, see Figure 1) viruses with different surface chemistries allowed the effect of particle shape on the osteogenesis of BMSCs to be determined. The results showed that four of these virus-based scaffolds accelerated and enhanced osteogenic differentiation of BMSCs.[40]

Analysis of the expression level of three osteogenic markers (Figure 3) showed that cells grown on all virus based substrates (TMV, TVCV, PVX, and TYMV), except the CPMV coated substrate exhibited enhanced expression of all three osteospecific genes (BMP2, osteocalcin (BGLAP), and osteopontin (SPP1)) compared to cells grown on bare PDL substrate. Comparison of the spherical-shaped viral particles showed that while TYMV-coated substrates increased BMP2 gene expression by 4 folds and dramatically enhanced expression of BGLAP and SPP1, there was no significant difference in these gene expressions between cells plated on PDL and CPMV substrates. An interpretation of this result where the same shape virus particles do not necessarily promote stem cell differentiation is that the shape of the virus nanoparticle is not the major or only cue leading to the enhanced osteogenesis of BMSCs.[40]
A

Bone morphogenetic protein 2

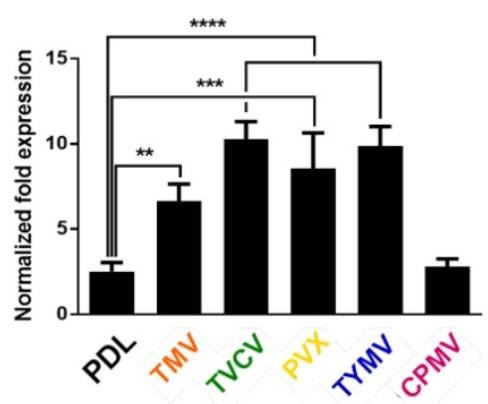

B

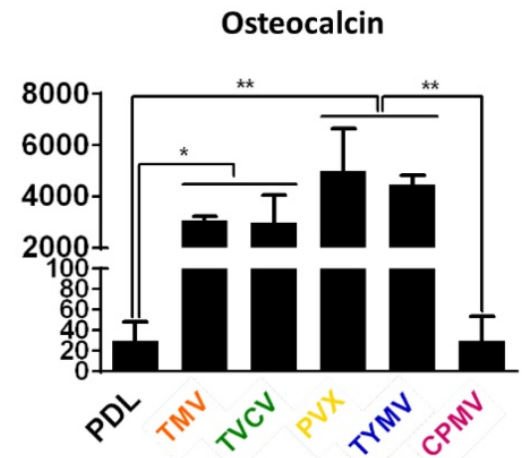

C

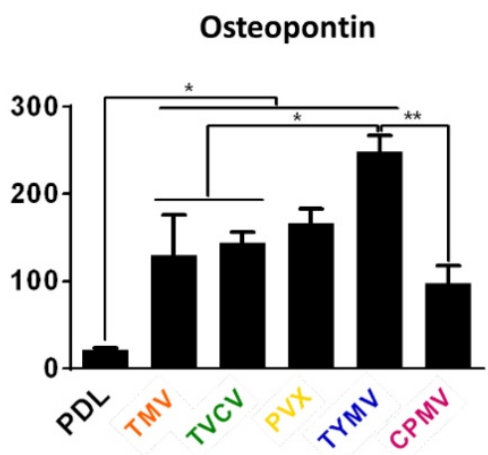

Figure 3. RT-qPCR analysis showed significant osteogenic markers upregulation in cells grown on TMV, TVCV, PVX, and TYMV (but not on CPMV). (A) BMP2 gene expression was analyzed 6 hours after osteogenic induction. (B) Osteocalcin and (C) Osteopontin genes expression were analyzed on day 7 after osteogenic induction. This result suggests early osteoblastic differentiation of BMSCs on the four virus coated substrates. 
Corroborating the gene expression data are immunofluorescence imaging of BMP2 (Figure 4) and osteocalcin (Figure 5), which revealed the localization of the morphogens in the cell aggregates on the four virus coated substrates.[40] BMSCs cultured on the substrates coated with TMV, TVCV, PVX, and TYMV developed greater cell nodules, a prominent feature of BMSCs undergoing osteogenesis. Additionally, these cell clusters displayed strong positive staining for BMP2 in cell aggregates (Figure 6), whereas no fluorescence signal was detected in cells grown on the PDL control and CPMV substrates. Likewise, at day 14 the osteocalcin marker was found exclusively in cells aggregates on TMV, TVCV, PVX, and TYMV substrates as determined by immunohistochemical staining.[40]
Consistent with the analysis of osteo-specific markers, analysis of alkaline phosphatase (ALP) activity and calcium mineralization also supported the osteogenic differentiation of cells on the four virus based scaffolds. Cytochemical analysis of the osteogenesis process of BMSCs on PDL and virus coated substrates at day 4 and 7 after osteogenic induction suggested that cells on TMV, TVCV, PVX, and TYMV substrates had an increase in ALP activity at day 4, whereas the enzyme activity was not altered on CPMV substrates when compared to PDL control. For cells on TMV and TVCV substrates, the enzyme activity fell to baseline at day 7 (Figure 6A), suggesting that cells on these two virus substrates differentiated and started mineralization earlier than cells on other substrates.[66]

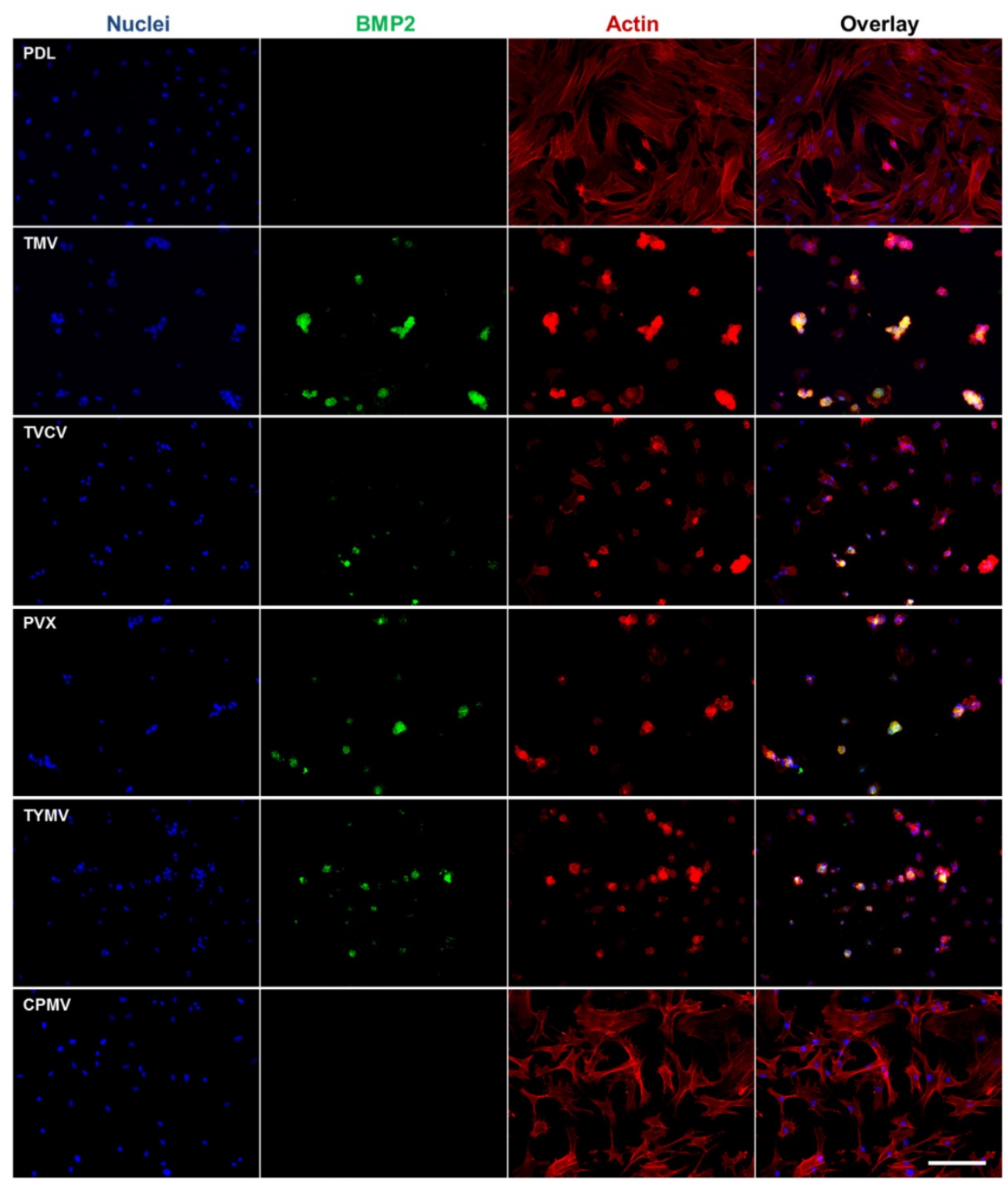

Figure 4. BMP2 immunohistochemical staining suggests the protein expressions are localized to the cell aggregates; most are found on TMV, TVCV, PVX, and TYMV substrates. Scale bar is $200 \mu \mathrm{m}$. Color representation: nucleus (blue), BMP2 (green), actin (red). Reproduced with permission from ref 36 . Copyright 2015 Wiley Online Library. 

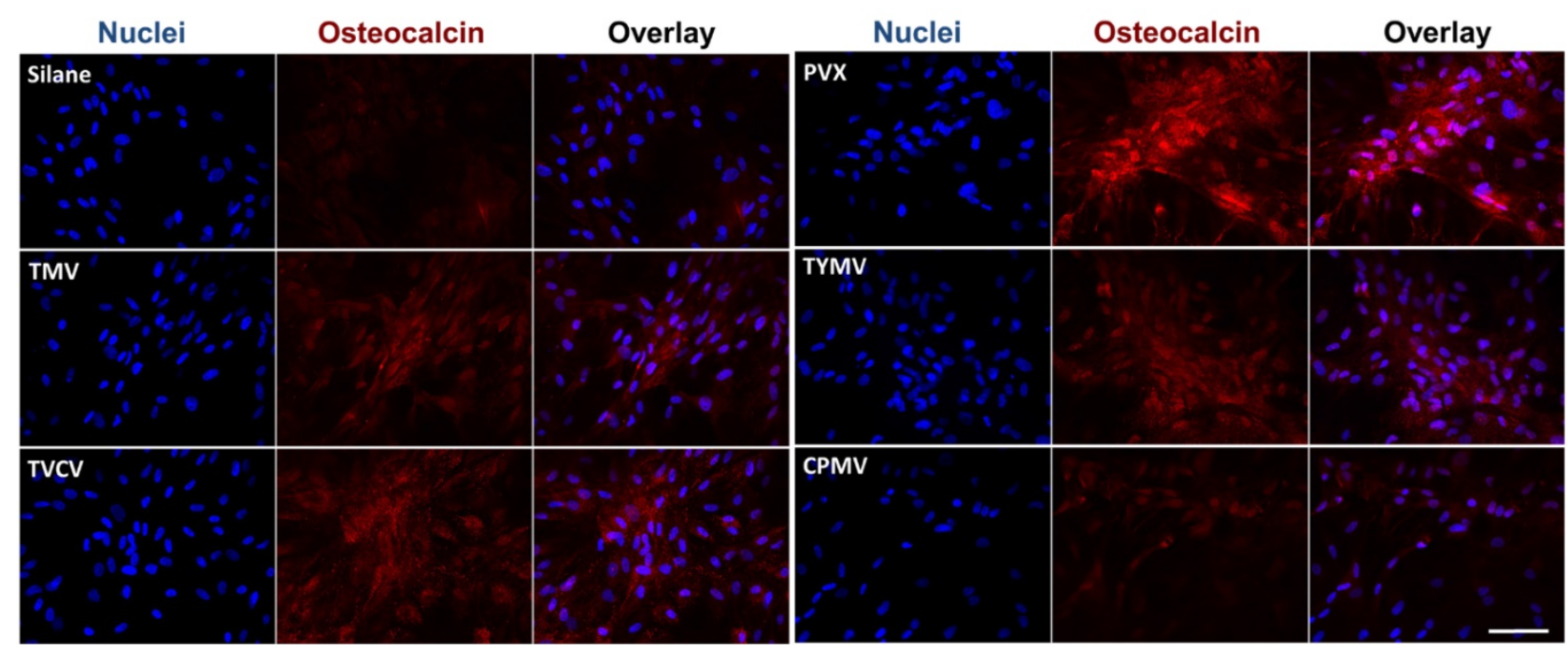

Figure 5. The Immunohistochemical staining of osteocalcin in BMSCs cultured on PDL and different virus nanoparticles coated substrates under osteogenic conditions. Immunohistochemical staining reveals that osteocalcin, a canonical osteogenic marker, is exclusively located in cell aggregates growing on TMV, TVCV, PVX, and TYMV substrates (not for CPMV coated substrate). Color representation: nucleus (blue), osteocalcin (red). Scale bar is $100 \mu \mathrm{m}$.
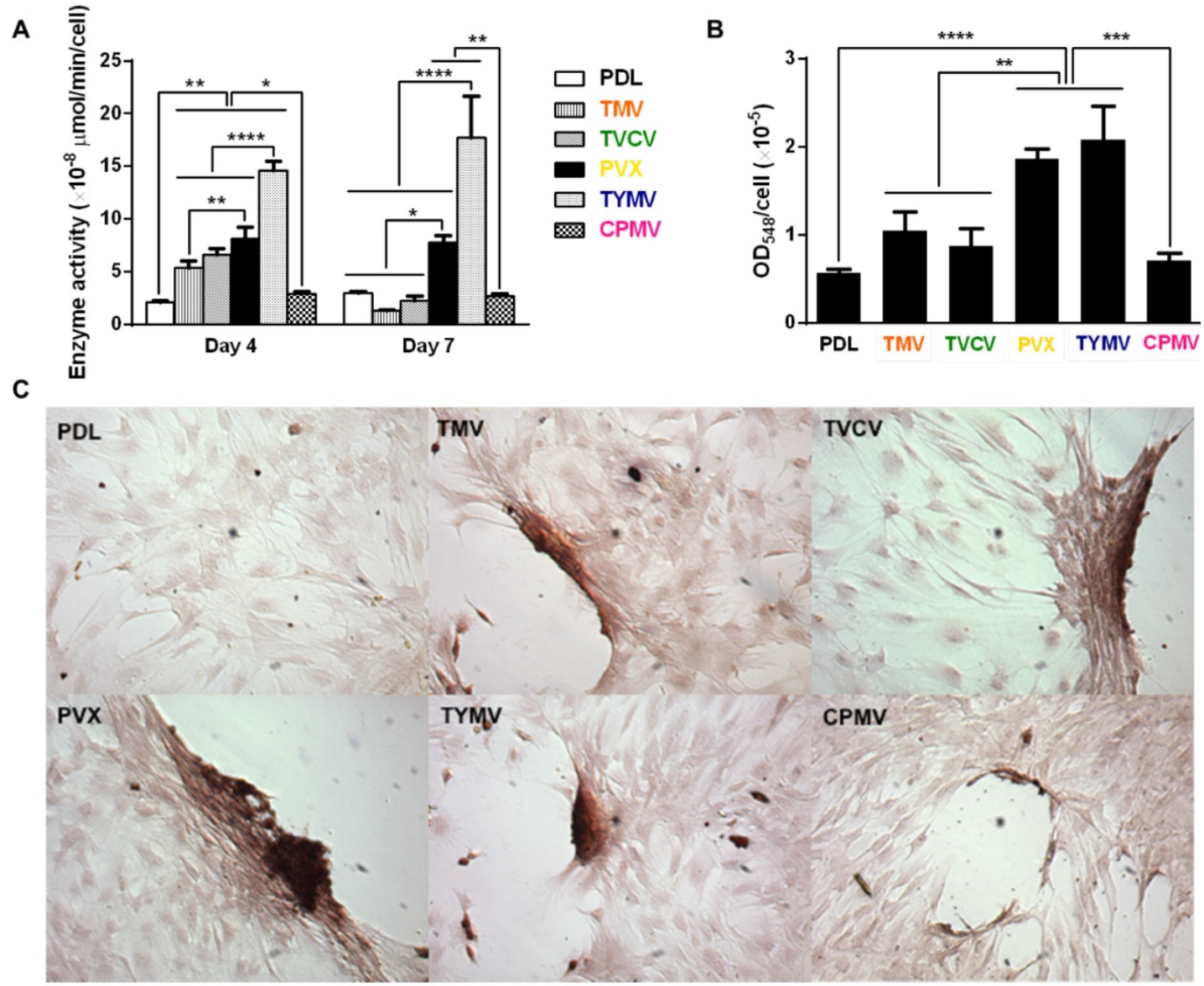

Figure 6. Cytochemical analysis of the bone differentiation process of BMSCs on PDL and viruses coated substrates at 4 and 7 days after osteogenic induction. (A) Alkaline phosphatase activity of cells cultured on different substrates. Cells on TMV, TVCV, PVX, and TYMV substrates have an increase in enzyme activity at day 4, while the enzyme activity of cells on CPMV substrates is not different from cells cultured on PDL control. On day 7, alkaline phosphatase activity reduces to baseline for cells on TMV and TVCV substrates. The data are expressed as mean \pm s.d. $(n=3, * p \leq 0.05$, ** $p \leq 0.01, * * * * p \leq 0.0001$ based on ANOVA) (B) Absorbance at $548 \mathrm{~nm}$ is normalized to cell number to indicate a relative amount of calcium deposit at day 7 stained by alizarin red solution. The mineralization of cells on TMV substrates doubles that of PDL, while PVX and TYMV substrates increase the mineralization by 4 folds. TVCV substrates slightly increase the mineralization of cells compare to PDL control substrates. These evidences suggest an improvement in osteogenesis by virus coated substrates. The data are expressed as mean \pm s.d. ( $\mathrm{n}$ $=3, * * p \leq 0.01, * * * p \leq 0.001, * * * * p \leq 0.0001$ based on ANOVA). (C) Alizarin red staining of each sample at day 7 . Cells on virus substrates are positively stained for calcium deposition, whereas negatively stain is observed on PDL substrates. Reproduced with permission from ref 36. Copyright 2015 Wiley Online Library. 
Additionally, cells on the four virus substrates at day 7 were positively stained by Alizarin red S, which showed deep red color for calcium deposition in large cell nodules, whereas negative stain was observed on PDL substrates (Figure 6B). The nodules in cells on CPMV substrate were also stained with Alizarin red $S$, however, they were much smaller compared to nodules in the other four virus substrates. Quantification by UV-Vis absorbance of the dissolved Alizarin red S dye from the cell nodules indicated that the mineralization of cells relative to that on PLD was doubled on TMV substrates, and quadrupled on the PVX and TYMV substrates, but only insignificantly increased on TVCV substrates (Figure 6C). However, given that the calcium mineralization accumulates, the difference in calcium deposition between each substrate and the difference of the mineralization between cells on TVCV and PDL coated substrates could increase at a longer incubation time. As expected, cells on CPMV substrate have comparable calcium mineralization to cells on PDL control.

The combined results from RT-qPCR, immunohistochemical staining, enzyme activity and calcium mineralization unambiguously indicate that TMV, TVCV, PVX, and TYMV substrates can accelerate and enhance osteogenesis of BMSCs. In this study, the researchers have confirmed that it is the topography created by deposition of virus nanoparticles on substrates and not the underlying material that mediates such differentiation.

\section{Modification of Viral Particles Can Augment the Cellular Responses}

The different degree of cellular modulation by substrates coated with same shape wild type viruses in the study by Metavarayuth et al. suggested that surface topography is important for osteogenic differentiation. Indeed several studies looked into the effect of modified surface chemistry of virus nanoparticles on the differentiation of stem cells. These studies typically compared cellular responses on wild-type virus coated substrates to those on modified virus-coated substrates. The modification can be achieved through either chemical or genetic modifications. Furthermore, through chemical or genetic modifications, the symmetrical arrangement of the repeating protein subunits of the virus nanoparticles serves as a handle to display functional groups in a controllable and multivalent fashion.

\section{Chemically modified virus particles enhance cellular responses}

The iconic rod shape TMV has been used in many studies as a model to display multivalent functional ligands in high density and highly ordered arrangement for BMSCs differentiation. Kaur et al. introduced functional phosphate for calcium incorporation onto each of $2130 \mathrm{TMV}$ protein subunits via the copper(I) catalyzed azide-alkyne cycloaddition (CuAAC) reaction. ${ }^{33}$ TMV-phosphate substrate displayed significantly higher up-regulation of osteocalcin and osteopontin during BMSCs differentiation as compared to wild-type TMV substrate. From day 7 to day 14 and 21, cells on TMV-phosphate transformed to a more polygonal-like shape from a well-spread morphology. More importantly, when deposited on Ti substrate, TMV-phosphate showed improved osteogenic differentiation of BMSCs,[67] highlighting the potential application for bone tissue engineering.

Chemical modification of the TMV coat protein by click chemistry was also employed to display multivalent peptide fragments on TMV particle. Sitasuwan et al. utilized $\mathrm{CuAAC}$ reaction to click azide-derivatized RGD peptides to the tyrosine residues of TMV outer surface. The RGD-functionalized TMV particles were then directly deposited onto 2D substrate, where they enhanced initial BMSCs adhesion and promoted osteogenesis compared to wild-type TMV coated substrates.[68]

\section{Genetically engineered mutant virus particles improve cellular responses}

Besides chemical modification of the virus coat protein, genetic mutation was also employed to alter the surface chemistry of the virus nanoparticles. Lee $e t$ al. created a library of mutants TMV with cell-binding peptide fragments from different extracellular matrix proteins inserted near the carboxyl end of TMV coat protein in order to gain better understanding of multivalent interaction between cells and extracellular matrix.[31] Multivalent interactions between cell surface receptors and the binding ligands are crucial for cellular function.[69, 70] It is known that the density and arrangement of the ligands play an important role in initial cell adhesion as well as the activation of the signaling processes leading to different differentiation pathways.[71] Indeed, cell adhesion studies revealed that RGD peptide inserted TMV mutants can augment cell attachment to virus substrate better than mutants integrated with peptide fragments from fibronectin and collagen proteins. The library created by Lee et al. provided alternative TMV mutants with enhanced cell-material interaction and cell adhesion, which can ultimately promote cell differentiation. In a follow-up study by Lee et al., one of the TMV mutants (TMV-RGD1) was shown to induce rapid onset of key bone differentiation makers, such as osteocalcin and BMP-2 in BMSCs within two days in serum-free osteogenic media (Figure 7).[58] 

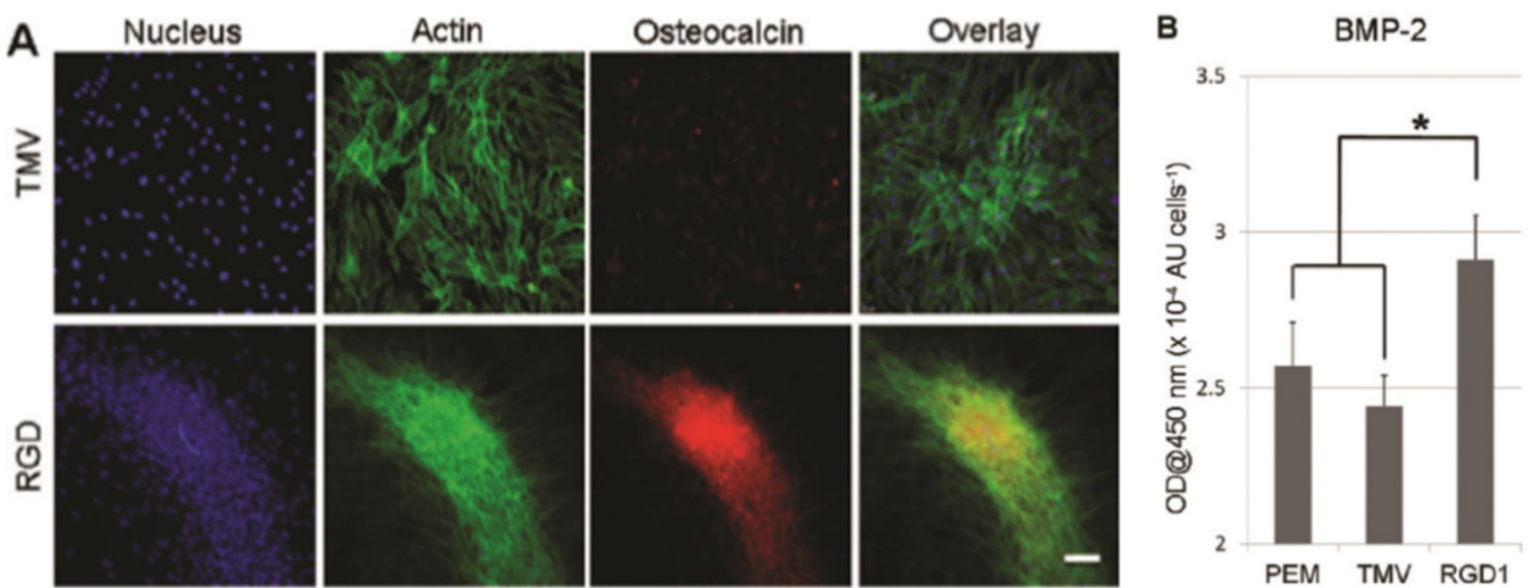

Figure 7. TMV-RGDI mutant induces rapid bone differentiation of BMSCs in serum-free osteogenic media after 2 days of induction (A) A canonical osteogenic marker, osteocalcin, is exclusively found on cell aggregates growing on TMV-RGDI coated substrates. For cells on TMV, the isolated cells express low levels of osteocalcin. Nucleus stained with DAPI (blue), actin stained phalloidin-FITC (green), and osteocalcin (red). (B) BMP-2 expression, an early marker of osteogenesis, was quantified by probing with anti-BMP2 primary antibody followed by anti-mouse goat IgG-HRP with TMB solution. Error bars denote \pm SEM ( $\mathrm{I}=12$ ). ${ }^{*} \mathrm{P}<0.05$ using two-tailed equal variance Student t test comparing TMV-RGD1 to all substrates.

Apart from TMV, other plant viruses have also been inserted with peptide fragments to promote cell adhesion and alter cell differentiation.[31, 72-74] In a study by Zan et al., an RGD motif was genetically displayed on the coat protein of the TYMV capsid. Composite films composed of either wild-type TYMV or TYMV-RGD44, in combination with poly (allylamine hydrochloride) (PAH), were fabricated by a layer-by-layer adsorption of virus and PAH.[57] The deposition process was confirmed by quartz crystal microbalance, UV-visible spectroscopy and atomic force microscopy. BMSC adhesion assays showed enhanced cell adhesion and spreading on TYMV-RGD44 coated substrates compared to native TYMV.

Another virus that has been extensively studied for osteogenic differentiation is M13 bacteriophages. Yoo et al. reported a M13 matrix engineered with collagen-derived DGEA-peptides that could induce the osteogenic differentiation of pre-osteoblasts with outgrown morphology and osteogenic protein expression.[75] Mao and co-workers fabricated aligned virus films with genetically engineered M13 to observe MSCs responses on different peptide sequences (Figure 8).[38] One of the sequences was PDPLEPRREVCE, which was derived from osteocalcin,[76] and another was YGFGG, the core domain of the osteogenic growth peptide.[77] These peptides were ligated to the major coat protein of M13 phages, and were displayed on the side walls of M13 surface (PD-phage and YG-phage). MSCs cultured on wild type (WT) phage and YG-phage film demonstrated a spindle-like cellular morphology with significant elongation and alignment along the phage bundles. While cells seeded on the PD-phage films were more spread out with several filopodia protrusion. It was reported that the elongation and stretching of hMSCs favored the osteogenic lineage commitment.[78] Further studies were designed to test if the engineered phage films could specifically promote the differentiation of MSCs into osteoblasts.[38] When cultured in osteogenic media for 2 weeks, higher expression levels of osteocalcin and osteopontin were observed in MSCs seeded on the WT, YG-, and PD-phage films compared to poly-lysine film. MSCs grown on the PD-phage film aggregated to form calcified nodule-like structures because of the strong negative charge $(-35 \mathrm{mV})$ on the PD-phage surface, which would attract the calcium ions to induce mineralization. Gene expression analysis confirmed that MSCs on both WT and engineered-phage films showed significantly higher upregulation of osteoblast gene expression than poly-lysine film. Specifically, the YG-phage could significantly up-regulate expression of Runx2, a master transcription factor in MSCs differentiation, [79] as compared to WT or PD-phage film, which indicated that the YG peptide regulated the MSCs growth and differentiation into osteoblast cells via Runx2 pathway.[80] Mineralization study also showed that MSCs on phage films have 1.5 times more calcium-containing matrix cells than non-phage containing films (Figure 8B-D).

To study the effect of biological cues on the osteoblastic differentiation of MSCs, the other peptides including RGD and PHSRN were displayed on M13 in their follow-up research.[34] The results indicated that the displayed functional peptides could induce the osteoblastic differentiation of MSCs in the primary media without any osteogenic supplements and could be further enhanced in osteogenic media. 

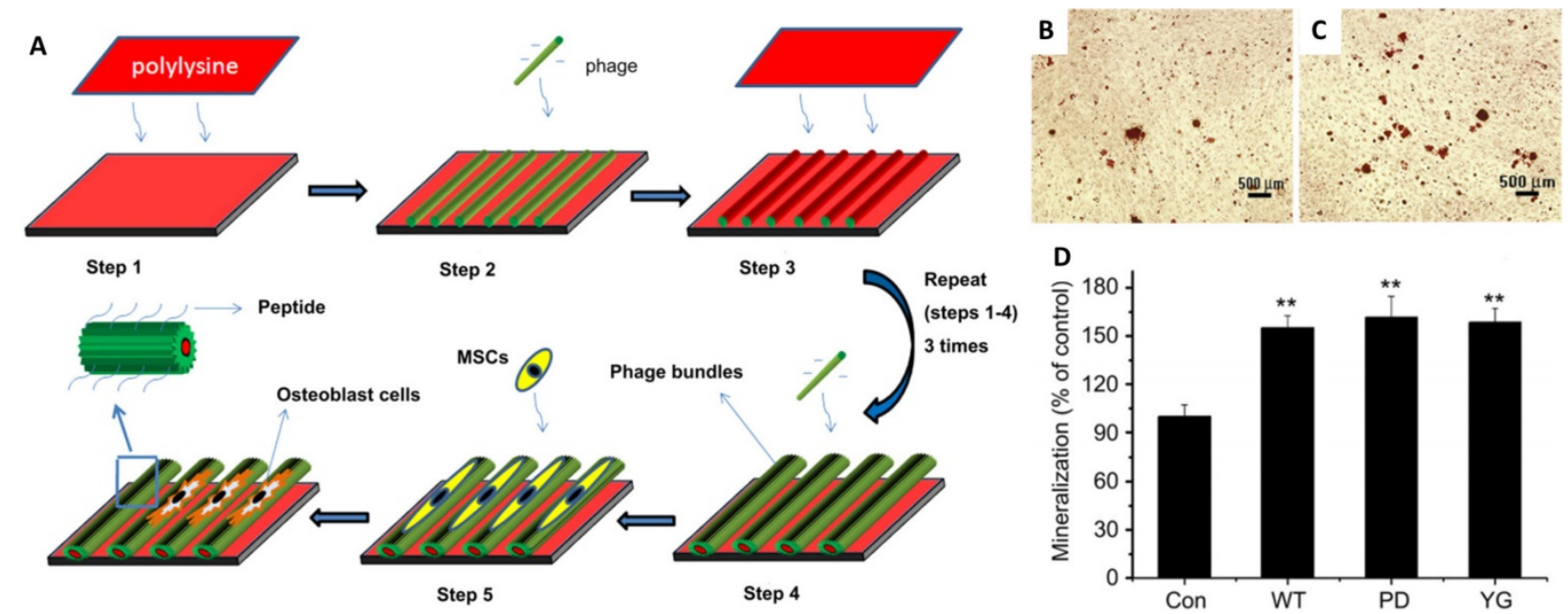

Figure 8. Schematic illustration of the formation of the phage film by using layer-by-layer method and the MSCs growth on the phage film. The phage nanofibers were assembled into parallel aligned bundles separated by grooves. The resulted pattern directed MSCs orientation along the phage bundles. (A) The functional peptides displayed on the phage surface (PD and YG) combined with the effect of stretched morphology stimulated the MSCs osteogenesis as shown by mineralization assay. (B-D) Optical images of mineralized nodules on MSCs cultured on films derived from glass slide with poly-lysine coated (control) (B) and PD-phage (C). The levels of mineralization formed by MSCs seeded on the different types of substrates (D). Adapted with permission from ref 34 . Copyright 2011 Elsevier

\section{Plant virus functionalized 3-D scaffolds for bone differentiation}

The superior osteogenic differentiation potentials of wild-type and mutant virus substrates can also be translated to 3D scaffolds. Luckanagul et al. constructed porous alginate hydrogels (PAH) functionalized with TMV (TMV-PAH) and TMV-RGD1 mutant (RGD-PAH).[80, 81] As shown in Figure 9A, the BMSCs could adhere to the hydrogels and spread out. Due to the RGD sequence, RGD-PAH showed significant improvement in cell attachment at $8 \mathrm{~h}$, and exhibited the highest cell metabolic activity at day 8 as compared to PAH and TMV-PAH. In addition, RGD-PAH accelerated osteogenesis of BMSCs, whose ALP activity was significantly higher among three samples on day 3 (Figure 9B). The amount of calcium deposited in both TMV-PAH and RGD-PAH were significantly higher than that in PAH (Figure 9C). Moreover, the accumulation of osteospecific markers, such as osteocalcin, at day 10 for PAH and day 13 for both TMV-PAH and RGD-PAH, indicated that virus incorporation into 3D matrices did not impair the differentiation potential of BMSCs into osteogenic lineage. Similarly, an injectable hydrogels has been developed by Maturavongsadit et al. to mimic the cartilage microenvironment using hyaluronic acid (HA) derivatives as starting materials.[82] Cysteine-inserted TMV mutant (TMV1cys) was incorporated into methacrylated hyaluronic acid (MeHA) polymers by thiol-ene "click" chemistry to form hydrogels under physiological condition. The resulting hydrogels could promote in vitro chondrogenesis of BMSCs as well as the expression of
BMP-2 proteins.

A later study by Luckanagul et al. showed that the plant virus incorporated hydrogels possessed extremely low immunogenicity in an in vivo study with mouse model.[83] In a rat model with cranial bone defect, TMV-functionalized hydrogel scaffolds showed great biocompatibility when implanted in the defect site.[84] The rats showed no sign of distress and the weight gains were comparable to those in the control group. Furthermore, neither increase in white blood cells counts nor spleen weight change or organ damage was observed from the blood test results from different time points after implantation. More importantly, this versatile bionanoparticle-based hydrogel platform can support bone regeneration and ultimately repair the cranial defect in laboratory rats based on the results from two analyses: (1) micro computed tomography (microCT) and (2) histological analysis of tissue excises using Masson's trichrome staining technique. The results also suggested that the bone regeneration could be accelerated by incorporating TMV particles into the 3D hydrogel scaffold.[84]

\section{Mechanistic Analysis of the Nanotopographical Cues Offered by Viral Scaffolds}

The adhesion strength of cells to a substrate can influence cell shape and size[85] In addition, integrin-mediated focal adhesion has been shown to be an important regulator of osteogenesis. $[86,87]$ It is hypothesized that too strong of a cell-substrate binding may inhibit osteogenic differentiation. This hypothesis is supported by observation made by 
Mendonça et al. whereby osteogenic differentiation was higher for stem cells that attached weakly on rough titanium disks than for cells that attached strongly on smooth substrate.[88] This lower observed osteogenic differentiation in tightly attached cells could possibly be due to the limitation of cell movement or migration. The strength of cell adhesion and larger focal adhesion size are correlated to an increase in localization of vinculin, a protein of the focal adhesion complexes (FAC).[89] For native virus coated substrates, cells seem to adhere more loosely on these surfaces as indicated by analysis of vinculin using fluorescence imaging.[40, 63] The study by Matavarayuth et al. showed that the average focal adhesion sizes were reduced when cells were grown on PDL and TMV, TVCV, PVX, and TYMV but not CPMV substrates for 24 hours prior to osteoinduction (Figure 10).

These results suggest that BMSCs attached to
TMV, TVCV, PVX, and TYMV substrates weakly, whereas the larger size of FACs dictated stronger cell-substrate adhesion in PDL and CPMV substrates.[90] The significantly smaller focal adhesion (FA) size for cells on the TMV, TVCV, PVX, and TYMV substrates might increase cellular motility and facilitate the formation of cell aggregates within 6 hours of osteoinduction. The larger FA size observed in CPMV sample, which did not improve osteogenic differentiation, might be attributed to the expression of vimentin binding ligand on CPMV coat proteins.[91] The vimentin cytoskeleton is shown to regulate focal contact size and helps to stabilize cell-matrix adhesion in endothelial cells.[92] Since vimentin is a major cytoskeletal component of mesenchymal cells, the presence of vimentin-binding ligands on CPMV substrate could supply additional adhesion points and consequently led to higher adhesion strength of cells.
A

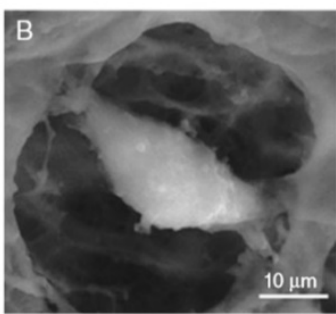

B

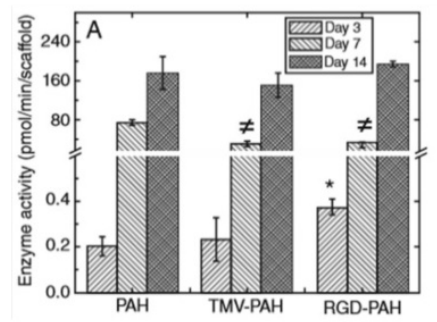

C

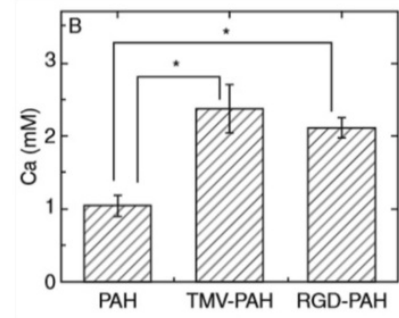

D
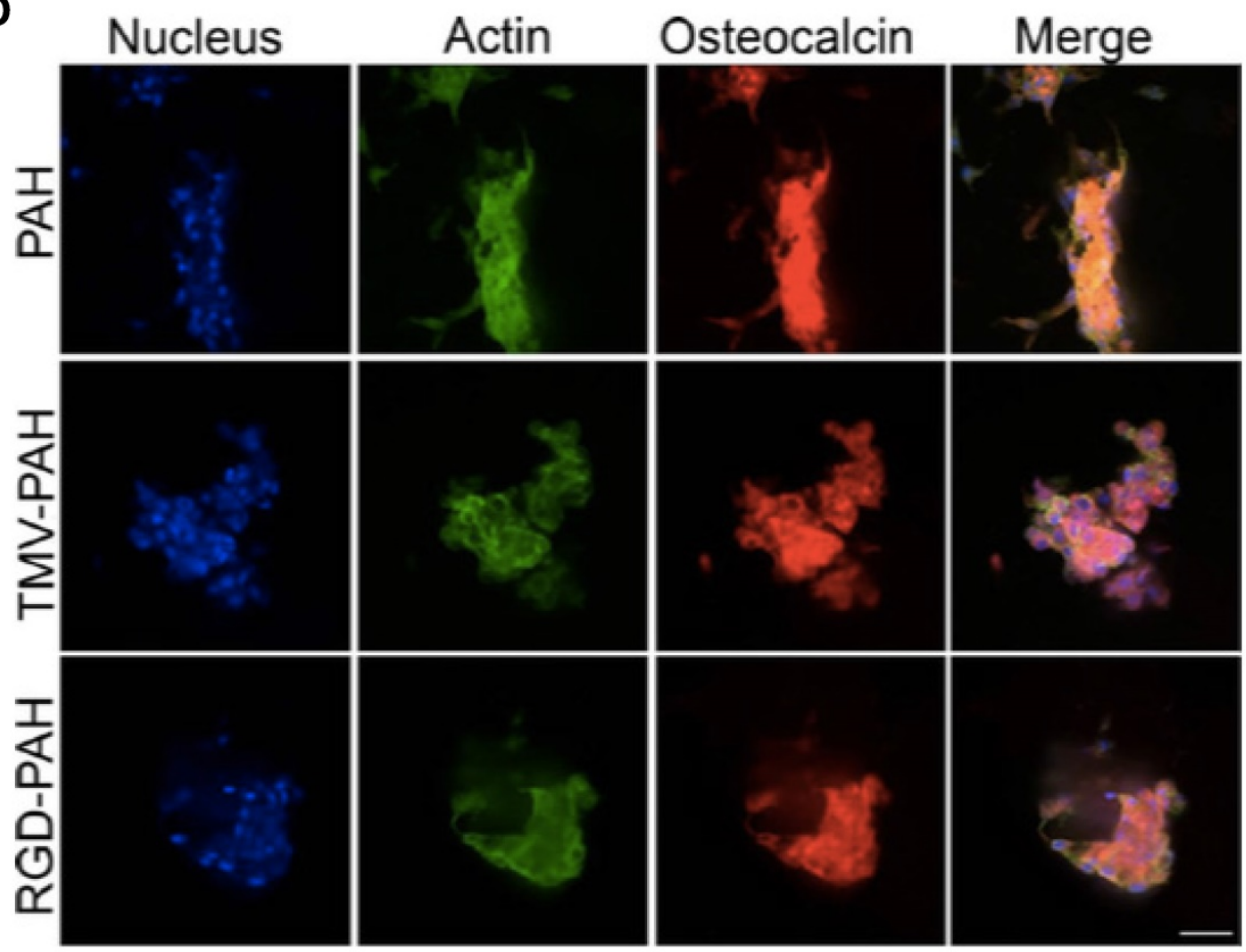

Figure 9. (A) SEM images of a single cell inside TMV-PAH. (B) Alkaline phosphatase activity assay of BMSCs (P <0.05). (C) Calcium deposition of BMSCs quantified on day $6(P<0.05)$. (D) Confocal images of differentiated BMSCs in 3D composite hydrogels stained for nucleus (blue), actin (green), and osteocalcin (red) illustrated the accumulation of osteocalcin after day $10(\mathrm{PAH})$ and day $13(\mathrm{TMV}-\mathrm{PAH}$ and RGD-PAH). Scale bar $=50 \mu \mathrm{m}$. 
A

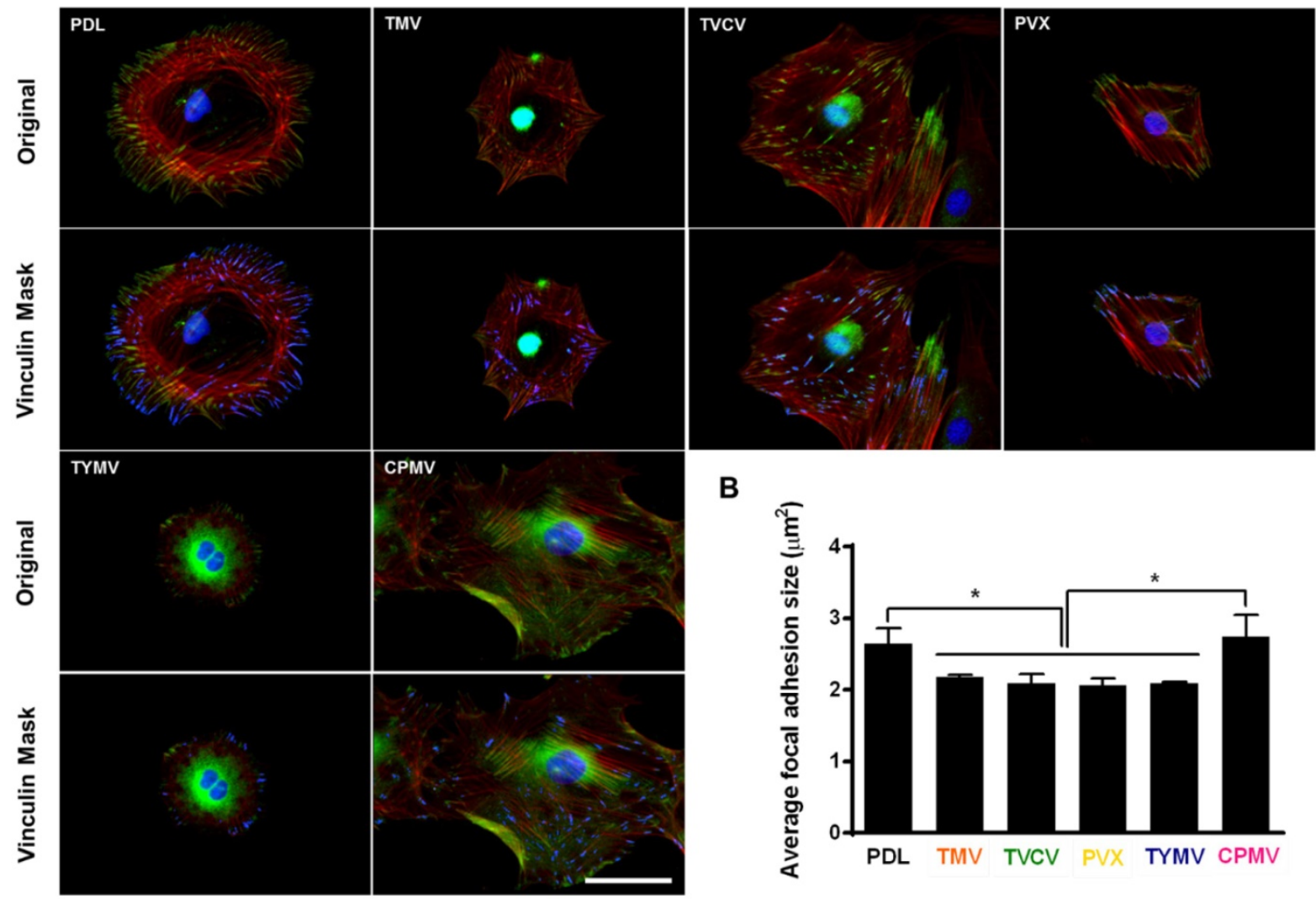

Figure 10. Immunochemical staining showing the difference in vinculin size from cells on PDL or virus coated substrates for 24 hours. (A) Immunofluorescence images of cells on different substrates at 24 hours prior to osteoinduction (top panel). Color representation: nucleus (blue), vinculin (green), phalloidin (red). The bottom panel demonstrates vinculin masking and selection of vinculins for size analysis. The selected vinculin spots are highlighted in blue. Scale bar is $50 \mu$ m. (B) Average vinculin size of cells on different substrates. The data were expressed as mean \pm s.d. $(n=3$, * represents $p \leq 0.05$ based on ANOVA). Reproduced with permission from ref 36. Copyright 2015 Wiley Online Library

Several reports have previously described that elongated shapes and geometries that present features of subcellular concavity at the cell perimeter increase the cytoskeletal tension in mesenchymal stem cells (MSCs), thus promoting the preference for osteogenesis.[93, 94] These similar geometries of BMSCs were also observed in the five viruses substrates study for the aforementioned virus substrates that promoted osteogenesis of BMSCs. Representative actin and vinculin immunofluorescent heat maps of cells initially adhered on PDL and each virus-coated substrate confirmed that cells on TMV, TVCV, PVX, and TYMV were more elongated with higher actin stress fiber on the long axis of cells. Additionally, the majority of them had concave features that led to high cytoskeleton tension in the region. Furthermore, vinculin proteins of cells that grew on these four substrates were highly localized at the protrusion area, in contrast to those of cells on PDL and CPMV coated substrates. The majority of cells on PDL and CPMV coated substrates were rounded in shape with evenly distribute actin filaments and vinculin around cell perimeter (Figure 11). Moreover, the overall morphology of cells on each virus substrate, which can be investigated from Figure 5 and Figure 10, reveals that cells on CPMV have a more spread out shape compared to cells on other virus substrates. The morphology data and immunofluorescence heatmaps, along with small FA size suggest that loose attachment of cells on the four unfriendly virus (TMV, TVCV, PVX, and TYMV) coated substrates resulted in cytoskeleton tension, thereby enhancing osteogenic differentiation of BMSCs.

Interestingly, the effect of nanoparticle morphology on differentiation is negligible; as observed from all experiments, osteogenic differentiation is comparable in cells cultured on substrates coated with different shapes of viruses. Additionally, cells differentiation can be different on same shape of virus coated substrates as distinct results were observed from BMSCs on substrates coated with TYMV or CPMV, both of which are spherical virus nanoparticles. 

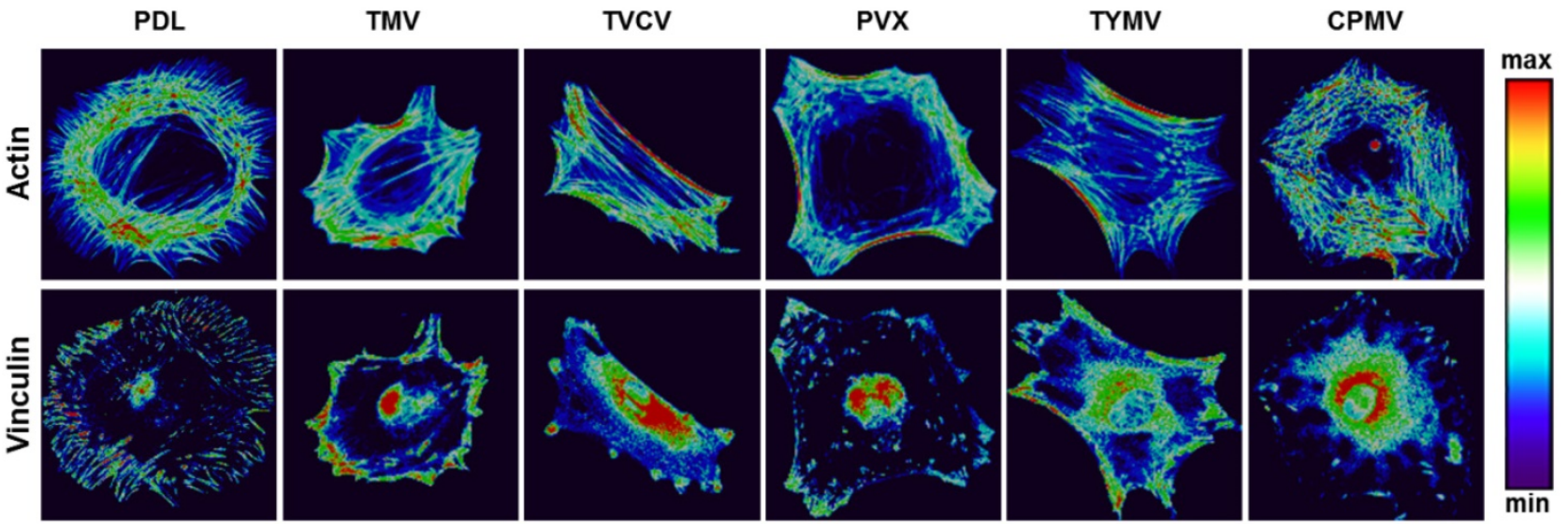

Figure 11. Representative actin (top panel) and vinculin (bottom panel) immunofluorescent heat maps of cells culture on PDL and virus coated substrates. Reproduced with permission from ref 36. Copyright 2015 Wiley Online Library

There are several signaling cascades that cells use to confer information about their cellular microenvironment through integrins, a group of transmembrane proteins that bind to ECM proteins, such as collagen, fibronectin, laminin, and vitronectin. One of these major pathways is the MAPK/ERK pathway. Kearney et al. suggested that stress and strain from the extracellular matrix environment induce cell osteogenesis through 46 mitogen-activated protein kinases (MAPKs).[95] In addition, RhoA, a member of the larger Rho-family of GTPases, has been widely implicated to control cell migration[96-98] in integrin-mediated signaling.[99-101] Mediated in part by one of its downstream effectors, the Rho-associated protein kinase, or ROCK, RhoA plays a central role in the assembly of actin stress fibers in response to various stimuli.[102-104] RhoA has also been associated with the cellular response to mechanical stress and the maintenance of tensional homeostasis.[105-110] A number of studies have shown that RhoA regulates the switch between adipogenesis and myogenesis,[111] and that osteogenic commitment also relies on RhoA-ROCK signaling.[112] The nanotopography from virus substrates was shown to effect osteogenesis in the same fashion as other physical cues that induced cell differentiation. The signaling cascade (Figure 12) starts at the important integrin mechanoreceptors that sense the stimulation from the virus substrate and in turn activate ERK1/2 by activating FAK. The activated ERK1/2 leads to the expression of BMP2 through activation of NF-kB. Consequently, the increased BMP2 results in the activation of BMPs/Smad pathway and finally leads to the expression of Runx2 and other osteospecific genes. Matavarayuth et al. showed that inhibition of BMP2 by Noggin led to significantly reduced osteogenesis of BMSCs on TMV substrates in a concentration dependent manner.[59] This result verified BMP2 as the key modulator of virus coated substrate-mediated osteogenic differentiation of stem cells. The RhoA/ROCK pathway was suggested as the downstream cascade of the centralized BMP2 modulator, which supports by a study by Wang et al.[113] that demonstrated BMP2-induced osteogenesis regulated by RhoA/ROCK, cell shape, and cytoskeleton tension. In addition, PCR array screening for genes involved in the movement of cells on TMV substrates confirms the association of cell adhesion and migration processes to the osteogenic differentiation phenomenon.[56] Specifically, many genes that were significantly changed in expression level were associated with RhoA/ROCK pathway. More importantly, the treatment of cells on TMV substrate with ROCK inhibitor, Y27632 intensely attenuated osteoblastic differentiation of cells.[59]

Collectively, these results suggest that structural changes to the cytoskeleton play key roles in determining MSC differentiation. Although it is well established that RhoA affects focal adhesions and stress fibers, and plays a crucial role in determining osteogenic-adipogenic fate decisions,[112] the downstream effects of such factors on other MSC differentiation pathways are less clear.

\section{Conclusion and Perspective}

Success in tissue engineering depends on ability of biomaterials to mimic the extracellular matrix environment and display biological and topographical cues for controlled cell signaling. Interest in applying viral nanoparticle to tissue engineering has been drastically increased due to the capability of the bionanoparticles to modulate cell behaviors. The advantages of exploiting viruses as platforms to construct substrates for tissue engineering include the robustness of virus 
nanoparticles to genetic and chemical modifications to display biological cues for cellular activities,[114, 115] their ability to present functional molecules in a multivalent and often high density fashion to enhance the cell-material interaction, $[58,116]$ and a variety of well-developed strategies to assemble virus nanoparticles into well-defined structures with nanoscale topography in two and three dimensions.[114] Specifically for 2D scaffolds, direct deposition and layer-by-layer assembly are highly employed. Although, the latter creates highly uniform virus-coated surface, the biocompatibility of the assembled system is still in question. On the other hand, while direct deposition of virus suffers from unpredictable surface roughness, it has created virus-coated substrates that could support cell proliferation, direct cell orientation and promote cell differentiation. The examples discussed in this review demonstrate the ability of virus-based biomaterial to regulate differentiation of bone marrow derived mesenchymal stem cells to osteoblasts, suggesting their potential application in bone tissue engineering.

The underlying mechanisms for the enhanced osteogenesis of BMSCS on native as well as genetically- or chemically-modified viruses coated on substrates is proposed to be related to the stress created by the unfavorable surface from nanotopographical cues of viral nanoparticles. This stress causes the reduction in FA size, which in turn increases cell motility and facilitates the formation of cell aggregates. The unfavorable surface may also obstruct cell spreading and, therefore, increase cytoskeleton tension, which results in a high aspect ratio or subcellular concavity at the cell perimeter, thus promoting osteogenesis. The proposed signaling cascade of virus-substrate-mediated osteogenesis of MSCs initiates when integrin senses the nanotopographical cues of the virus particles and upregulates BMP2 production through activation of the MAPK/ERK pathway. The key BMP2 protein then induces osteogenesis via RhoA/ROCK signaling pathway.

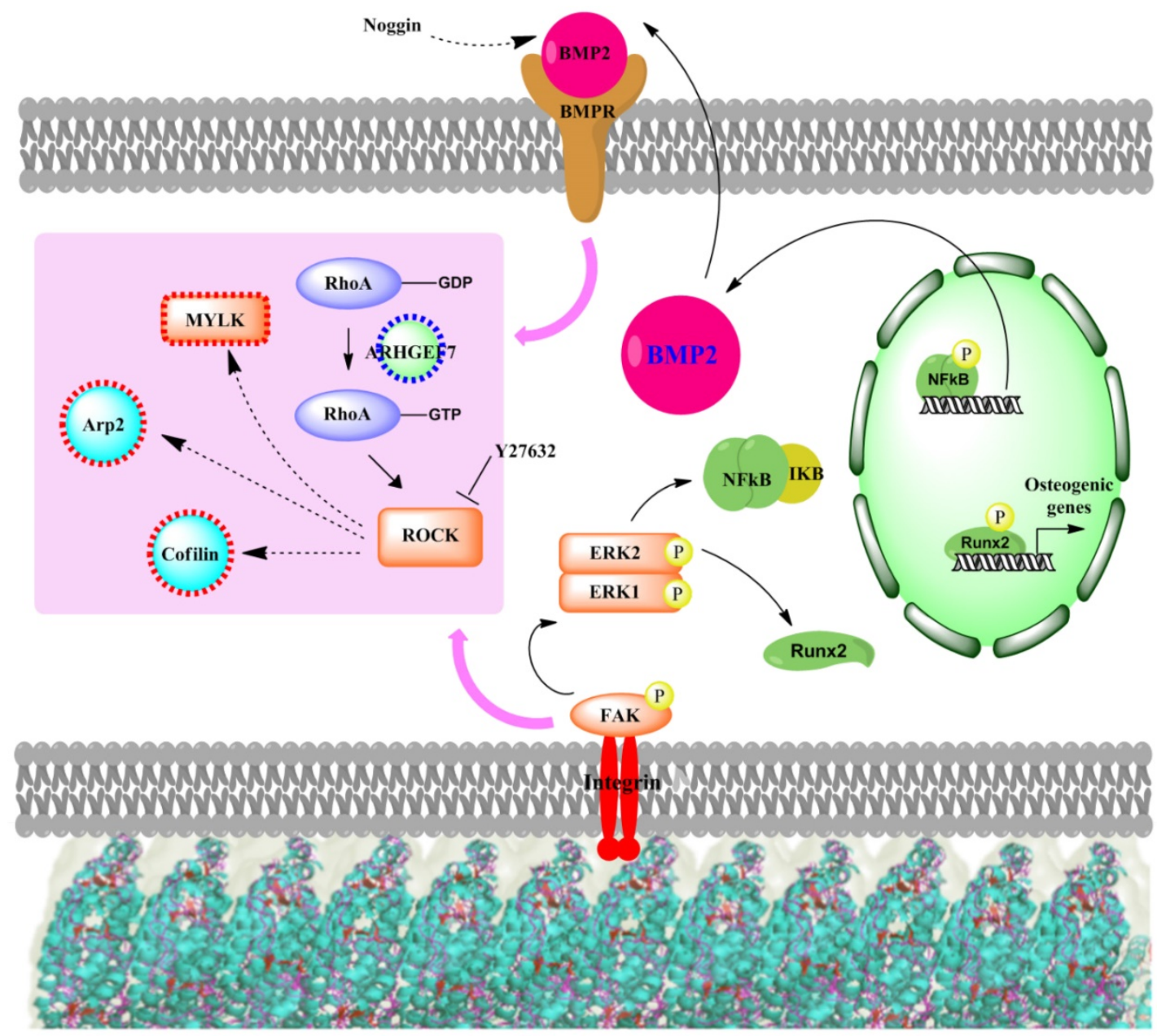

Figure 12. Proposed signaling cascade of virus substrates mediated osteogenesis of MSCs. 
While much progress has been made using 2D virus-coated substrates to conduct fundamental studies on the osteogenesis of BSMCs, there remain challenges for virus scaffolds in tissue engineering application. For example, virus-based biomaterials lack the desirable elastic stiffness and compressive strength to serve as ideal scaffolds for bone tissue engineering.[117] Considering the future clinical application, the potential toxicity of the virus nanoparticles in the human body must be also be addressed, with evaluation of the potential immune responses and the inflammatory reactions cause by the nanoparticles. On the other hand, we can envision designing synthetic scaffolds that mimic the nanotopographical cues of virus-coated substrates to stimulate the osteogenic related differentiation of stem cells, which might offer an innovative strategy to design bone regeneration materials.[26, 118]

\section{Competing Interests}

The authors have declared that no competing interest exists.

\section{References}

1. Kaur G, Valarmathi MT, Potts JD, Wang Q. The promotion of osteoblastic differentiation of rat bone marrow stromal cells by a polyvalent plant mosaic virus. Biomaterials. 2008; 29: 4074-81.

2. Jiang $Y$, Jahagirdar $B N$, Reinhardt RL, Schwartz RE, Keene $C D$, Ortiz-Gonzalez XR, et al. Pluripotency of mesenchymal stem cells derived from adult marrow. Nature. 2002; 418: 41-9.

3. Minguell JJ, Erices A, Conget P. Mesenchymal stem cells. Experimental biology and medicine. 2001; 226: 507-20.

4. Pittenger MF, Mackay AM, Beck SC, Jaiswal RK, Douglas R, Mosca JD, et al. Multilineage potential of adult human mesenchymal stem cells. Science. 1999; 284: 143-7.

5. Si YL, Zhao YL, Hao HJ, Fu XB, Han WD. MSCs: Biological characteristics, clinical applications and their outstanding concerns. Ageing research reviews. 2011; 10: 93-103.

6. Mackay AM, Beck SC, Murphy JM, Barry FP, Chichester CO, Pittenger MF. Chondrogenic differentiation of cultured human mesenchymal stem cells from marrow. Tissue engineering. 1998; 4: 415-28.

7. Drost AC, Weng S, Feil G, Schafer J, Baumann S, Kanz L, et al. In vitro myogenic differentiation of human bone marrow-derived mesenchymal stem cells as a potential treatment for urethral sphincter muscle repair. Annals of the New York Academy of Sciences. 2009; 1176: 135-43.

8. Oswald J, Boxberger S, Jorgensen B, Feldmann S, Ehninger G, Bornhauser M, et al. Mesenchymal stem cells can be differentiated into endothelial cells in vitro. Stem cells. 2004; 22: 377-84

9. Gong Z, Calkins G, Cheng EC, Krause D, Niklason LE. Influence of culture medium on smooth muscle cell differentiation from human bone marrow-derived mesenchymal stem cells. Tissue engineering Part A. 2009; 15: 319-30.

10. Porada CD, Almeida-Porada G. Mesenchymal stem cells as therapeutics and vehicles for gene and drug delivery. Advanced drug delivery reviews. 2010; 62: 1156-66.

11. Lee CH, Shin HJ, Cho IH, Kang YM, Kim IA, Park KD, et al. Nanofiber alignment and direction of mechanical strain affect the ECM production of human ACL fibroblast. Biomaterials. 2005; 26: 1261-70.

12. Andersson AS, Brink J, Lidberg U, Sutherland DS. Influence of systematically varied nanoscale topography on the morphology of epithelial cells. IEEE transactions on nanobioscience. 2003; 2: 49-57.

13. Fukushima $\mathrm{N}$, Ohkawa $\mathrm{H}$. Hematopoietic stem cells and microenvironment: the proliferation and differentiation of stromal cells. Critical reviews in oncology/hematology. 1995; 20: 255-70.

14. Bashur CA, Dahlgren LA, Goldstein AS. Effect of fiber diameter and orientation on fibroblast morphology and proliferation on electrospun poly(D,L-lactic-co-glycolic acid) meshes. Biomaterials. 2006; 27: 5681-8.

15. Dalby MJ, Gadegaard N, Wilkinson CD. The response of fibroblasts to hexagonal nanotopography fabricated by electron beam lithography. Journal of biomedical materials research Part A. 2008; 84: 973-9.

16. Stevens $\mathrm{MM}, \mathrm{George} \mathrm{JH}$. Exploring and engineering the cell surface interface. Science. 2005; 310: 1135-8.
17. Draghi L, Cigada A. Nanostructured surfaces for biomedical applications. Part I: nanotopography. Journal of applied biomaterials \& biomechanics : JABB. 2007; 5: 61-9.

18. Miller DC, Thapa A, Haberstroh KM, Webster TJ. Endothelial and vascular smooth muscle cell function on poly(lactic-co-glycolic acid) with nano-structured surface features. Biomaterials. 2004; 25: 53-61.

19. Badami AS, Kreke MR, Thompson MS, Riffle JS, Goldstein AS. Effect of fiber diameter on spreading, proliferation, and differentiation of osteoblastic cells on electrospun poly(lactic acid) substrates. Biomaterials. 2006; 27: 596-606.

20. Arnold M, Cavalcanti-Adam EA, Glass R, Blummel J, Eck W, Kantlehner M, et al. Activation of integrin function by nanopatterned adhesive interfaces. Chemphyschem : a European journal of chemical physics and physical chemistry. 2004; 5: 383-8.

21. He J, Zhou W, Zhou X, Zhong X, Zhang X, Wan P, et al. The anatase phase of nanotopography titania plays an important role on osteoblast cell morphology and proliferation. Journal of materials science Materials in medicine. 2008; 19: 3465-72.

22. Mendonca G, Mendonca DB, Aragao FJ, Cooper LF. Advancing dental implant surface technology--from micron- to nanotopography. Biomaterials. 2008; 29: 3822-35.

23. Yim EK, Reano RM, Pang SW, Yee AF, Chen CS, Leong KW. Nanopattern-induced changes in morphology and motility of smooth muscle cells. Biomaterials. 2005; 26: 5405-13.

24. Wan Y, Wang Y, Liu Z, Qu X, Han B, Bei J, et al. Adhesion and proliferation of OCT-1 osteoblast-like cells on micro- and nano-scale topography structured poly(L-lactide). Biomaterials. 2005; 26: 4453-9.

25. Liu Q, Cen L, Yin S, Chen L, Liu G, Chang J, et al. A comparative study of proliferation and osteogenic differentiation of adipose-derived stem cells on akermanite and beta-TCP ceramics. Biomaterials. 2008; 29: 4792-9.

26. Bachhuka A, Delalat B, Ghaemi SR, Gronthos S, Voelcker NH, Vasilev K. Nanotopography mediated osteogenic differentiation of human dental pulp derived stem cells. Nanoscale. 2017

27. Chen W, Villa-Diaz LG, Sun Y, Weng S, Kim JK, Lam RH, et al. Nanotopography influences adhesion, spreading, and self-renewal of human embryonic stem cells. ACS Nano. 2012; 6: 4094-103.

28. Dalby MJ, Gadegaard N, Oreffo RO. Harnessing nanotopography and integrin-matrix interactions to influence stem cell fate. Nat Mater. 2014; 13: 558-69.

29. Jungbauer S, Kemkemer R, Gruler H, Kaufmann D, Spatz JP. Cell shape normalization, dendrite orientation, and melanin production of normal and genetically altered (haploinsufficient NF1)-melanocytes by microstructured substrate interactions. Chemphyschem : a European journal of chemical physics and physical chemistry. 2004; 5: 85-92.

30. Wen AM, Steinmetz NF. Design of virus-based nanomaterials for medicine, biotechnology, and energy. Chemical Society Reviews. 2016; 45: 4074-126.

31. Lee LA, Nguyen QL, Wu L, Horvath G, Nelson RS, Wang Q. Mutant plant viruses with cell binding motifs provide differential adhesion strengths and morphologies. Biomacromolecules. 2012; 13: 422-31.

32. Pokorski JK, Steinmetz NF. The art of engineering viral nanoparticles. Molecular pharmaceutics. 2011; 8: 29-43.

33. Chung WI, Merzlyak A, Yoo SY, Lee SW. Genetically engineered liquid-crystalline viral films for directing neural cell growth. Langmuir : the ACS journal of surfaces and colloids. 2010; 26: 9885-90.

34. Wang J, Wang L, Li X, Mao C. Virus activated artificial ECM induces the osteoblastic differentiation of mesenchymal stem cells without osteogenic supplements. Scientific reports. 2013; 3: 1242.

35. Merzlyak A, Indrakanti S, Lee SW. Genetically engineered nanofiber-like viruses for tissue regenerating materials. Nano Lett. 2009; 9: 846-52.

36. Destito G, Yeh R, Rae CS, Finn MG, Manchester M. Folic acid-mediated targeting of cowpea mosaic virus particles to tumor cells. Chemistry \& biology. 2007; 14: 1152-62.

37. Gerasopoulos K, McCarthy M, Banerjee P, Fan X, Culver JN, Ghodssi R Biofabrication methods for the patterned assembly and synthesis of viral nanotemplates. Nanotechnology. 2010; 21: 055304.

38. Zhu H, Cao B, Zhen Z, Laxmi AA, Li D, Liu S, et al. Controlled growth and differentiation of MSCs on grooved films assembled from monodisperse biological nanofibers with genetically tunable surface chemistries. Biomaterials. 2011; 32: 4744-52.

39. Deegan RD, Bakajin O, Dupont TF, Huber G, Nagel SR, Witten TA. Capillary flow as the cause of ring stains from dried liquid drops. Nature. 1997; 389: $827-9$.

40. Metavarayuth K, Sitasuwan P, Luckanagul JA, Feng S, Wang Q. Virus Nanoparticles Mediated Osteogenic Differentiation of Bone Derived Mesenchymal Stem Cells. Advanced Science. 2015; 2.

41. Steinmetz NF, Findlay KC, Noel TR, Parker R, Lomonossoff GP, Evans DJ. Layer-by-layer assembly of viral nanoparticles and polyelectrolytes: the film architecture is different for spheres versus rods. Chembiochem. 2008; 9: 1662-70.

42. Rong J, Niu Z, Lee LA, Wang Q. Self-assembly of viral particles. Current Opinion in Colloid \& Interface Science. 2011; 16: 441-50.

43. Suci PA, Klem MT, Arce FT, Douglas T, Young M. Assembly of multilayer films incorporating a viral protein cage architecture. Langmuir : the ACS journal of surfaces and colloids. 2006; 22: 8891-6.

44. Yoo PJ, Nam KT, Qi J, Lee SK, Park J, Belcher AM, et al. Spontaneous assembly of viruses on multilayered polymer surfaces. Nature materials. 2006; 5: 234-40. 
45. Yoo PJ, Nam KT, Belcher AM, Hammond PT. Solvent-assisted patterning of polyelectrolyte multilayers and selective deposition of virus assemblies. Nano Lett. 2008; 8: 1081-9.

46. Fuoss RM, Sadek H. Mutual Interaction of Polyelectrolytes. Science. 1949; 110: $552-4$.

47. Lvov Y, Haas H, Decher G, Moehwald H, Mikhailov A, Mtchedlishvily B, et al. Successive Deposition of Alternate Layers of Polyelectrolytes and a Charged Virus. Langmuir : the ACS journal of surfaces and colloids. 1994; 10: 4232-6.

48. Decher G. Fuzzy Nanoassemblies: Toward Layered Polymeric Multicomposites. Science. 1997; 277: 1232-7.

49. Dubas ST, Schlenoff JB. Factors Controlling the Growth of Polyelectrolyte Multilayers. Macromolecules. 1999; 32: 8153-60.

50. Tan HL, McMurdo MJ, Pan G, Van Patten PG. Temperature Dependence of Polyelectrolyte Multilayer Assembly. Langmuir : the ACS journal of surfaces and colloids. 2003; 19: 9311-4.

51. Büscher K, Graf K, Ahrens H, Helm CA. Influence of Adsorption Conditions on the Structure of Polyelectrolyte Multilayers. Langmuir : the ACS journal of surfaces and colloids. 2002; 18: 3585-91.

52. Clark SL, Montague MF, Hammond PT. Ionic Effects of Sodium Chloride on the Templated Deposition of Polyelectrolytes Using Layer-by-Layer Ionic Assembly. Macromolecules. 1997; 30: 7237-44.

53. Yoo D, Shiratori SS, Rubner MF. Controlling Bilayer Composition and Surface Wettability of Sequentially Adsorbed Multilayers of Weak Polyelectrolytes. Macromolecules. 1998; 31: 4309-18.

54. Glinel K, Moussa A, Jonas AM, Laschewsky A. Influence of Polyelectrolyte Charge Density on the Formation of Multilayers of Strong Polyelectrolytes at Low Ionic Strength. Langmuir : the ACS journal of surfaces and colloids. 2002; 18: 1408-12.

55. Zan X, Peng B, Hoagland DA, Su Z. Polyelectrolyte uptake by PEMs: Impact of salt concentration. Polymer Chemistry. 2011; 2: 2581-9.

56. Sitasuwan P. Biomaterial-Induced Osteogenesis of Mesenchymal Stem Cells by Surface Roughness and Functionalization. Columbia, SC: University of South Carolina; 2013.

57. Zan X, Sitasuwan P, Powell J, Dreher TW, Wang Q. Polyvalent display of RGD motifs on turnip yellow mosaic virus for enhanced stem cell adhesion and spreading. Acta biomaterialia. 2012; 8: 2978-85

58. Lee LA, Muhammad SM, Nguyen QL, Sitasuwan P, Horvath G, Wang Q. Multivalent Ligand Displayed on Plant Virus Induces Rapid Onset of Bone Differentiation. Molecular pharmaceutics. 2012; 9: 2121-5.

59. Metavarayuth K. Virus Particles Provide Nanotopographical Cues for Osteogenic Differentiation of Mesenchymal Stem Cells. Columbia, SC: University of South Carolina; 2016.

60. Gundberg CM, Hauschka PV, Lian JB, Gallop PM. Osteocalcin: isolation, characterization, and detection. Methods in enzymology. 1984; 107: 516-44.

61. Rodan GA, Noda M. Gene expression in osteoblastic cells. Critical reviews in eukaryotic gene expression. 1991; 1: 85-98.

62. Lian JB, Stein GS. Concepts of osteoblast growth and differentiation: basis for modulation of bone cell development and tissue formation. Critical reviews in oral biology and medicine : an official publication of the American Association of Oral Biologists. 1992; 3: 269-305.

63. Sitasuwan P, Lee LA, Bo P, Davis EN, Lin Y, Wang Q. A plant virus substrate induces early upregulation of BMP2 for rapid bone formation. Integrative biology : quantitative biosciences from nano to macro. 2012; 4: 651-60.

64. Kaur G, Valarmathi MT, Potts JD, Jabbari E, Sabo-Attwood T, Wang Q. Regulation of osteogenic differentiation of rat bone marrow stromal cells on 2D nanorod substrates. Biomaterials. 2010; 31: 1732-41.

65. Chen J, Singh K, Mukherjee BB, Sodek J. Developmental expression of osteopontin (OPN) mRNA in rat tissues: evidence for a role for OPN in bone formation and resorption. Matrix. 1993; 13: 113-23.

66. Tohme JF, Seibel MJ, Silverberg SJ, Robins SP, Bilezikian JP. Biochemical markers of bone metabolism. Zeitschrift fur Rheumatologie. 1991; 50: 133-41.

67. Kaur G, Wang C, Sun J, Wang Q. The synergistic effects of multivalent ligand display and nanotopography on osteogenic differentiation of rat bone marrow stem cells. Biomaterials. 2010; 31: 5813-24.

68. Sitasuwan P, Lee LA, Li K, Nguyen HG, Wang Q. RGD-conjugated rod-like viral nanoparticles on 2D scaffold improve bone differentiation of mesenchymal stem cells. Frontiers in chemistry. 2014; $2: 31$.

69. Mammen M, Choi S-K, Whitesides GM. Polyvalent Interactions in Biological Systems: Implications for Design and Use of Multivalent Ligands and Inhibitors. Angewandte Chemie International Edition. 1998; 37: 2754-94.

70. Kiessling LL, Gestwicki JE, Strong LE. Synthetic multivalent ligands as probes of signal transduction. Angewandte Chemie. 2006; 45: 2348-68

71. Ito Y. Surface micropatterning to regulate cell functions. Biomaterials. 1999; 20: 2333-42.

72. Zeng Q, Saha S, Lee LA, Barnhill H, Oxsher J, Dreher T, et al. Chemoselective modification of turnip yellow mosaic virus by $\mathrm{Cu}(\mathrm{I})$ catalyzed azide-alkyne 1,3-dipolar cycloaddition reaction and its application in cell binding. Bioconjug Chem. 2011; 22: 58-66.

73. Hovlid ML, Steinmetz NF, Laufer B, Lau JL, Kuzelka J, Wang Q, et al. Guiding plant virus particles to integrin-displaying cells. Nanoscale. 2012; 4: 3698-705.

74. Wang Q, Lin T, Johnson JE, Finn MG. Natural supramolecular building blocks. Cysteine-added mutants of cowpea mosaic virus. Chemistry \& biology. 2002; 9. $813-9$
75. Yoo SY, Kobayashi M, Lee PP, Lee SW. Early osteogenic differentiation of mouse preosteoblasts induced by collagen-derived DGEA-peptide on nanofibrous phage tissue matrices. Biomacromolecules. 2011; 12: 987-96.

76. Nielsen-Marsh CM, Richards MP, Hauschka PV, Thomas-Oates JE, Trinkaus E, Pettitt PB, et al. Osteocalcin protein sequences of Neanderthals and modern primates. Proceedings of the National Academy of Sciences of the United States of America. 2005; 102: 4409-13.

77. Moore NM, Lin NJ, Gallant ND, Becker ML. The use of immobilized osteogenic growth peptide on gradient substrates synthesized via click chemistry to enhance MC3T3-E1 osteoblast proliferation. Biomaterials. 2010; 31: 1604-11.

78. Dalby MJ, Gadegaard N, Tare R, Andar A, Riehle MO, Herzyk P, et al. The control of human mesenchymal cell differentiation using nanoscale symmetry and disorder. Nature materials. 2007; 6: 997-1003.

79. Huang J, Zhao L, Xing L, Chen D. MicroRNA-204 regulates Runx2 protein expression and mesenchymal progenitor cell differentiation. Stem cells. 2010; 28: 357-64.

80. Gabarin N, Gavish H, Muhlrad A, Chen YC, Namdar-Attar M, Nissenson RA, et al. Mitogenic G(i) protein-MAP kinase signaling cascade in MC3T3-E1 osteogenic cells: activation by C-terminal pentapeptide of osteogenic growth peptide [OGP(10-14)] and attenuation of activation by cAMP. Journal of cellular biochemistry. 2001; 81: 594-603.

81. Luckanagul J, Lee LA, Nguyen QL, Sitasuwan P, Yang X, Shazly T, et al. Porous Alginate Hydrogel Functionalized with Virus as Three-Dimensional Scaffolds for Bone Differentiation. Biomacromolecules. 2012; 13: 3949-58.

82. Maturavongsadit P, Luckanagul JA, Metavarayuth K, Zhao X, Chen L, Lin Y, et al. Promotion of In Vitro Chondrogenesis of Mesenchymal Stem Cells Using In Situ Hyaluronic Hydrogel Functionalized with Rod-Like Viral Nanoparticles. Biomacromolecules. 2016; 17: 1930-8.

83. Luckanagul JA, Lee LA, You S, Yang X, Wang Q. Plant virus incorporated hydrogels as scaffolds for tissue engineering possess low immunogenicity in vivo. J Biomed Mater Res A. 2015; 103: 887-95.

84. Luckanagul JA, Metavarayuth K, Feng S, Maneesaay P, Clark AY, Yang X, et al. Tobacco Mosaic Virus Functionalized Alginate Hydrogel Scaffolds for Bone Regeneration in Rats with Cranial Defect. ACS Biomaterials Science and Engineering. 2016; 2: 606-15.

85. Barnhart EL, Lee KC, Keren K, Mogilner A, Theriot JA. An adhesion-dependent switch between mechanisms that determine motile cell shape. PLoS biology. 2011; 9: e1001059.

86. Siebers MC, ter Brugge PJ, Walboomers XF, Jansen JA. Integrins as linker proteins between osteoblasts and bone replacing materials. A critical review. Biomaterials. 2005; 26: 137-46.

87. Garcia AJ, Reyes CD. Bio-adhesive surfaces to promote osteoblast differentiation and bone formation. Journal of dental research. 2005; 84: 407-13.

88. Mendonca DB, Miguez PA, Mendonca G, Yamauchi M, Aragao FJ, Cooper LF. Titanium surface topography affects collagen biosynthesis of adherent cells. Bone. 2011; 49: 463-72.

89. Mierke CT. The role of vinculin in the regulation of the mechanical properties of cells. Cell biochemistry and biophysics. 2009; 53: 115-26.

90. Katz BZ, Zamir E, Bershadsky A, Kam Z, Yamada KM, Geiger B. Physical state of the extracellular matrix regulates the structure and molecular composition of cell-matrix adhesions. Molecular biology of the cell. 2000; 11: 1047-60.

91. Koudelka KJ, Destito G, Plummer EM, Trauger SA, Siuzdak G, Manchester M. Endothelial targeting of cowpea mosaic virus (CPMV) via surface vimentin. PLoS pathogens. 2009; 5: e1000417.

92. Tsuruta D, Jones JC. The vimentin cytoskeleton regulates focal contact size and adhesion of endothelial cells subjected to shear stress. Journal of cell science. 2003; 116: 4977-84.

93. Kilian KA, Bugarija B, Lahn BT, Mrksich M. Geometric cues for directing the differentiation of mesenchymal stem cells. Proceedings of the National Academy of Sciences of the United States of America. 2010; 107: 4872-7.

94. Lee J, Abdeen AA, Huang TH, Kilian KA. Controlling cell geometry on substrates of variable stiffness can tune the degree of osteogenesis in human mesenchymal stem cells. Journal of the mechanical behavior of biomedical materials. 2014; 38: 209-18.

95. Kearney EM, Farrell E, Prendergast PJ, Campbell VA. Tensile strain as a regulator of mesenchymal stem cell osteogenesis. Annals of biomedical engineering. 2010; 38: 1767-79.

96. Etienne-Manneville S, Hall A. Rho GTPases in cell biology. Nature. 2002; 420: 629-35.

97. Hall A. Rho GTPases and the actin cytoskeleton. Science. 1998; 279: 509-14.

98. Wittmann T, Waterman-Storer CM. Cell motility: can Rho GTPases and microtubules point the way? Journal of cell science. 2001; 114: 3795-803.

99. Ren XD, Kiosses WB, Schwartz MA. Regulation of the small GTP-binding protein Rho by cell adhesion and the cytoskeleton. The EMBO journal. 1999; 18: $578-85$

100. Schoenwaelder SM, Burridge K. Bidirectional signaling between the cytoskeleton and integrins. Current opinion in cell biology. 1999; 11: 274-86.

101. Clark EA, King WG, Brugge JS, Symons M, Hynes RO. Integrin-mediated signals regulated by members of the rho family of GTPases. J Cell Biol. 1998; 142: $573-86$

102. Chong LD, Traynor-Kaplan A, Bokoch GM, Schwartz MA. The small GTP-binding protein Rho regulates a phosphatidylinositol 4-phosphate 5-kinase in mammalian cells. Cell. 1994; 79: 507-13. 
103. Chrzanowska-Wodnicka M, Burridge K. Rho-stimulated contractility drives the formation of stress fibers and focal adhesions. J Cell Biol. 1996; 133: 1403-15.

104. Nobes CD, Hall A. Rho, rac, and cdc42 GTPases regulate the assembly of multimolecular focal complexes associated with actin stress fibers, lamellipodia, and filopodia. Cell. 1995; 81: 53-62.

105. Putnam AJ, Cunningham JJ, Pillemer BB, Mooney DJ. External mechanical strain regulates membrane targeting of Rho GTPases by controlling microtubule assembly. American journal of physiology Cell physiology. 2003; 284: C627-39.

106. Matthews BD, Overby DR, Mannix R, Ingber DE. Cellular adaptation to mechanical stress: role of integrins, Rho, cytoskeletal tension and mechanosensitive ion channels. Journal of cell science. 2006; 119: 508-18.

107. Aikawa R, Komuro I, Yamazaki T, Zou Y, Kudoh S, Zhu W, et al. Rho family small $G$ proteins play critical roles in mechanical stress-induced hypertrophic responses in cardiac myocytes. Circulation research. 1999; 84: 458-66.

108. Aoki H, Izumo S, Sadoshima J. Angiotensin II activates RhoA in cardiac myocytes: a critical role of RhoA in angiotensin II-induced premyofibril formation. Circulation research. 1998; 82: 666-76.

109. Katsumi A, Milanini J, Kiosses WB, del Pozo MA, Kaunas R, Chien S, et al. Effects of cell tension on the small GTPase Rac. J Cell Biol. 2002; 158: 153-64.

110. Numaguchi K, Eguchi S, Yamakawa T, Motley ED, Inagami $T$. Mechanotransduction of rat aortic vascular smooth muscle cells requires RhoA and intact actin filaments. Circulation research. 1999; 85: 5-11.

111. Sordella R, Jiang W, Chen GC, Curto M, Settleman J. Modulation of Rho GTPase signaling regulates a switch between adipogenesis and myogenesis. Cell. 2003; 113: 147-58.

112. McBeath R, Pirone DM, Nelson CM, Bhadriraju K, Chen CS. Cell shape, cytoskeletal tension, and RhoA regulate stem cell lineage commitment. Developmental cell. 2004; 6: 483-95.

113. Wang YK, Yu X, Cohen DM, Wozniak MA, Yang MT, Gao L et al. Bone morphogenetic protein-2-induced signaling and osteogenesis is regulated by cell shape, RhoA/ROCK, and cytoskeletal tension. Stem cells and development. 2012; 21: 1176-86.

114. Lee LA, Niu $Z$, Wang $Q$. Viruses and virus-like protein assemblies - Chemically programmable nanoscale building blocks. Nano Res. 2009; 2: 349-64.

115. Fischlechner M, Donath E. Viruses as building blocks for materials and devices. Angewandte Chemie. 2007; 46: 3184-93.

116. Wu L, Zang J, Lee LA, Niu Z, Horvatha GC, Braxtona V, et al. Electrospinning fabrication, structural and mechanical characterization of rod-like virus-based composite nanofibers. Journal of Materials Chemistry. 2011; 21: 8550-7.

117. Rezwan K, Chen QZ, Blaker JJ, Boccaccini AR. Biodegradable and bioactive porous polymer/inorganic composite scaffolds for bone tissue engineering. Biomaterials. 2006; 27: 3413-31.

118. Karazisis D, Petronis S, Agheli H, Emanuelsson L, Norlindh B, Johansson A, et al. The influence of controlled surface nanotopography on the early biological events of osseointegration. Acta Biomater. 2017; 53: 559-71. 